\title{
Quantifying Rooftop Solar Benefits: a State-Level Value of Solar Analysis for India
}

January 2021

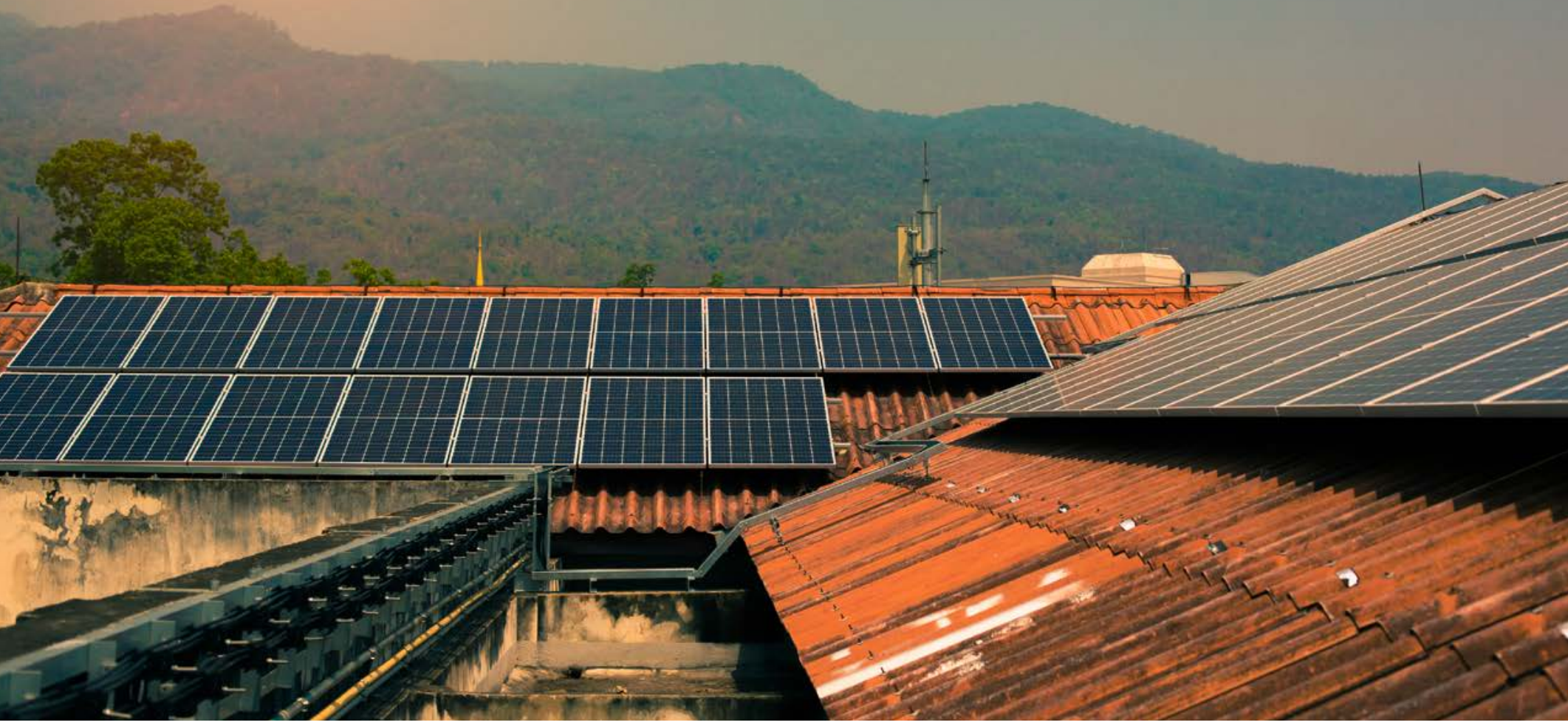




\section{Quantifying Rooftop Solar Benefits: a State-Level Value of Solar Analysis for India}

\section{Authors}

Thomas Bowen, Carishma Gokhale-Welch, Karlynn Cory, National Renewable Energy Laboratory; Golden, CO USA

Naïm Darghouth, Lawrence Berkeley National Laboratory; Berkeley, CA USA

January 2021 
Prepared by

\section{INREL}

\section{NOTICE}

This work was authored, in part, by the National Renewable Energy Laboratory (NREL), operated by Alliance for Sustainable Energy, LLC, for the U.S. Department of Energy (DOE) under Contract No. DE-AC36-08GO28308. Funding provided by the United States Agency for International Development (USAID) under Contract No. IAG-17-2050. The views expressed in this report do not necessarily represent the views of the DOE or the U.S. Government, or any agency thereof, including USAID.

This report is available at no cost from the National Renewable Energy Laboratory (NREL) at www.nrel.gov/publications.

U.S. Department of Energy (DOE) reports produced after 1991 and a growing number of pre-1991 documents are available free via www.OSTI.gov. 


\section{Acknowledgments}

This work was made possible through the U.S. Agency for International Development (USAID)-National Renewable Energy Laboratory (NREL) Partnership and in collaboration with the USAID Partnership to Advance Clean Energy Deployment 2.0. The authors thank Anurag Mishra from USAID-India and Sarah Lawson from the USAID Office of Energy and Infrastructure for their support of this work. We also wish to thank the following individuals for their detailed review comments, insights, and contributions to this report.

TetraTech: Rakesh Goyal, Ujjwal Bhattacharjee, Ronnie Khanna, and Devina Anand

NREL: Alexandra Aznar, Ilya Chernyakhovskiy, David Palchak, Linda Parkhill, Jane Pusch, and Owen Zinaman

Gujarat Energy Research and Management Institute: Akhilesh Magal

Prayas: Ashwin Gambhir and Ann Josey

Nexus Energytech Pvt Ltd: Arvind Karandikar

The authors would also like to thank Liz Breazeale and Britton Marchese of NREL for their editorial support. 


\section{List of Acronyms}

CAPEX

DER

DG

DISCOM

FOM

GJ

IEX

JH

MNRE

NREL

PV

RTS

SRMC

UCED

USAID

VDER

VOS

VRE capital expenditures

distributed energy resource

distributed generation

distribution company

fixed operating and maintenance

Gujarat

Indian Energy Exchange

Jharkhand

Ministry of New and Renewable Energy

National Renewable Energy Laboratory

photovoltaic

rooftop solar

short-run marginal cost

unit commitment and economic dispatch

U.S. Agency for International Development

value of distributed energy resources

value of solar

variable renewable energy 


\section{Executive Summary}

Driven by India's ambitious rooftop solar (RTS) goals, individual states have designed solar policies and compensation mechanisms to help achieve specific targets established for each state. As costs decline and these systems are more widely adopted, policymakers, regulators, and other stakeholders may want to better understand the net costs and benefits of RTS to adopting and nonadopting customers, the grid, distribution companies (DISCOMs), and other power system stakeholders. Indian utilities generally perceive RTS systems as impacting their revenues, as consumers begin meeting on-site load with RTS generation. This is particularly pronounced for customers such as commercial and industrial entities, on whom DISCOMs rely to pay higher rates to help subsidize consumption from lower-income and smaller residential customers. RTS is more attractive for these larger customers as their tariffs are higher and they have more access to capital and financing than smaller customers. As of June 2020, approximately $73 \%$ of RTS installed capacity was deployed by commercial and industrial customers (Bridge to India 2020). These higher rates of RTS adoption among larger customer classes could exacerbate existing financial issues for DISCOMs and make cost recovery more difficult (Josey et al. 2018; Zinaman et al. 2020).

These financial concerns can be addressed in part through changes to how RTS is compensated and to underlying retail tariffs for RTS customers. The Central Electricity Regulatory Commission and the Forum of Regulators recently updated the model regulations for RTS systems by allowing net billing and gross-metering at a rate defined by the state regulators. Likewise, some states (e.g., Gujarat and Maharashtra) have transitioned from net energy metering to net billing while other states have made efforts to do so (e.g., Karnataka). Finally, some states have suggested limits to RTS systems eligible for certain compensation mechanisms (e.g., Gujarat) and additional charges for interconnecting RTS systems (e.g., Maharashtra) (Zinaman et al. 2020). Analyses that quantify the costs and benefits associated with RTS adoption and operation can inform decision makers in the development and evaluation of RTS policies. One such analysis is a value of solar (VOS) study, which quantifies select costs and benefits surrounding RTS based on electricity system and other local data. These studies have been used in some jurisdictions to provide a data-driven evidence base to inform more cost-reflective RTS compensation or, alternatively, stay the course and largely maintain existing policies. These studies can also inform discussions around the unique contributions RTS provides to the power system relative to equivalent utility-scale generation, and how these contributions vary throughout the year or across a region. Such comparisons can be important when developing policies and planning for the optimal mix of generation in power system looking forward. Additionally, studies that offer more granular resolution (e.g., at the substate level) can inform policies and compensation mechanisms that help decision makers, power system operators and developers target deployment of RTS in areas of the grid where RTS generation provides the most benefit to all stakeholders.

This report provides a VOS analysis for two states in India: Gujarat and Jharkhand. The methodology considers four benefit categories (Energy, Generating Capacity, Transmission Capacity, and Environmental and Health), two cost categories (Program Administrative Costs and RTS Integration Costs), and two scenarios (existing levels of renewable energy capacity and significant capacity additions to meet established renewable energy targets). Between the two states analyzed, there are significant differences in power system sizes and generation mix, renewable energy targets and resource potential, as well as adopted compensation mechanisms. While there are some similarities in analysis results for each state, differences in the power system contexts outlined above have also led to significant differences in the values for RTS in the two states (Table 6, Section 3.3). The total VOS is lower in Jharkhand than in Gujarat, owing to the differences in Energy and Generating Capacity values (at existing solar photovoltaic $[\mathrm{PV}]$ penetrations). The lower relative Energy and Generating Capacity values in Jharkhand are, respectively, associated with lower overall electricity generation costs in Jharkhand and poor alignment between RTS generation and system peak demand in Jharkhand. 
Other key analysis findings include:

- The value of RTS is strongly context-dependent, based on underlying load patterns and generation mixes in the states of Jharkhand and Gujarat. As demand patterns and generation mixes in the two states, and in India more broadly, change, the VOS is also likely to change. In general, without interventions such as energy storage or additional transmission to export surplus renewable energy, solar PV's highly coincident generation pattern might lead to a lower VOS under higher solar penetrations. This analysis suggests that additional installed capacity of RTS and utility-scale solar PV in line with stated government goals could suppress the VOS in Gujarat but would minimally impact the VOS in Jharkhand. Gujarat has a target of over $12 \mathrm{GW}$ of RTS and utility-scale solar under Ministry of New and Renewable Energy (MNRE) goals, while Jharkhand has a target of less than $1 \mathrm{GW}$ of combined RTS and utility-scale solar capacity under MNRE goals.

- Grid exports from RTS in both states, under both scenarios considered, can help reduce the operating and capital costs associated with running the power system. Under today's renewable energy penetration levels and RTS installed capacity (Base Case), the marginal value of RTS generation is 4.8 rupees per $\mathrm{kWh}$ of RTS generation for Gujarat and 2.3 rupees per $\mathrm{kWh}$ for Jharkhand. These values are calculated as the combined Energy, Generating Capacity and Transmission Capacity values at the current RTS installed capacity levels in each state. Under expected renewable energy penetration levels given stated government goals (MNRE Goals), including new RTS capacity installations, the marginal VOS drops to 3.8 rupees per $\mathrm{kWh}$ for Gujarat and 2.3 rupees per kWh for Jharkhand. The lower value for Jharkhand is influenced by its lower electricity generation costs and demand pattern. The larger drop in value in Gujarat between the two scenarios is largely due to the exceedingly high level of solar PV expected in the state under government goals.

- Separate from the operating and capital benefits that accrue to the DISCOM above, RTS provides significant environmental and health benefits to society, including addressing climate change and reduced deaths and complications associated with pollutants from conventional electricity generation. This Environmental and Health value is in the range of 5.2 rupees per $\mathrm{kWh}$ and 7.0 rupees per $\mathrm{kWh}$ across both states and both scenarios. These values are calculated as the product of estimates for the emissions rate of an average coal power plant and for the health costs associated with an increase of a given pollutant (see Table A-4 for estimate values and sources). Air quality in India is, on average, exceedingly poor; according to the World Health Organization's 2018 Global Ambient Air Quality Database, 13 of the top 20 cities by annual average concentration of $\mathrm{PM}_{2.5}$ were in India (World Health Organization 2019). This poor air quality has profound impacts on the health of the populace: Of the total deaths in India for 2017, $12.5 \%$ could be attributed to air pollution, approximately 0.67 million of those deaths due to ambient particulate matter pollution (Balakrishnan et al. 2019). While only a portion of these deaths are associated with pollution from conventional electric generation, reducing air pollution from conventional electricity generation has the potential to reduce this number of deaths; indeed, our findings indicate that RTS has substantial health benefits resulting from reduced NOx, SOx, and particulate emissions.

- Taking the Environment and Health value into consideration, the VOS in both states for today's penetrations of renewable energy exceeds the retail tariff and compensation rate for both states (less than 5 rupees per kWh in Gujarat, less than 6.25 rupees per $\mathrm{kWh}$ in Jharkhand). This indicates that RTS exports and self-consumption provide a net benefit to society in the two states. These benefits, however, do not accrue solely to DISCOMs who must financially compensate RTS exports or who see reduced sales from RTS self-consumption. Our analysis suggests that the 
short-term VOS is 2.3-4.6 INR/kWh across the scenarios considered for Gujarat and Jharkhand, when the Environmental and Health value is excluded, which is lower than the present average retail tariff and compensation rates in the two states. Mechanisms such as emissions markets and carbon markets for generators may ensure more accurate sharing of the environmental and health benefits of RTS with all power system stakeholders. More accurate price signals, in turn, can help ensure more socially and economically optimal investments in RTS and other power system assets. While such mechanisms have the risk of complicating utility revenue recovery and increasing tariffs for low-income customers, additional policy interventions can help ensure other policy objectives (such as energy affordability) are not negatively impacted (see the Policy Options to Equitably Distribute Environmental and Health Benefits of RTS textbox in Section 4.2).

Policymakers, regulators, and other power system stakeholders can use the results from this analysis to determine whether compensation mechanisms for RTS should be revised in light of concerns around costshifting between RTS-adopting and RTS-nonadopting customers. In combination with revenue impact analyses, which calculate the costs associated with RTS self-consumption and compensation, VOS analyses can quantify the net impact of RTS on DISCOMs and ratepayers. This data-driven approach to RTS compensation can both drive RTS adoption where it is most beneficial as well as maintain RTS deployment without exacerbating cost-shifting concerns. While the methodology behind VOS analyses will depend on numerous factors, this report also includes a VOS Lite analysis using a simple Excel model and publicly available data that can be utilized by any jurisdictions interested in estimating the benefits and costs of RTS adoption in their region (Appendix B). 


\section{Table of Contents}

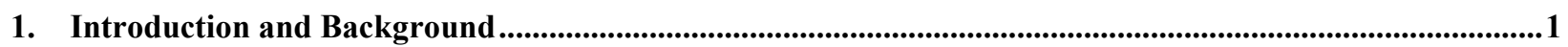

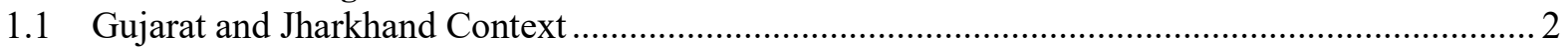

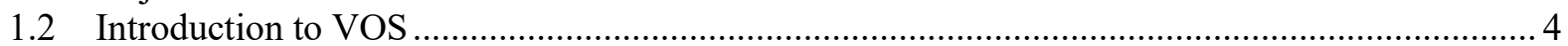

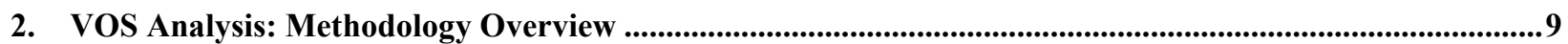

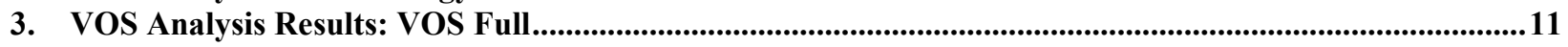

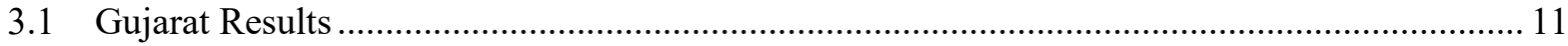

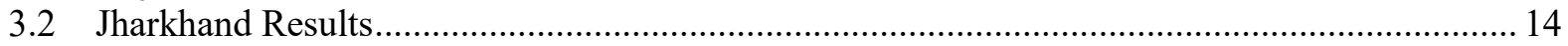

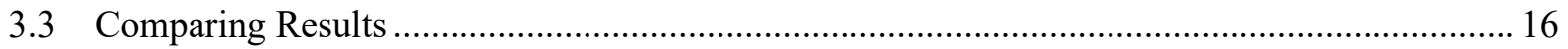

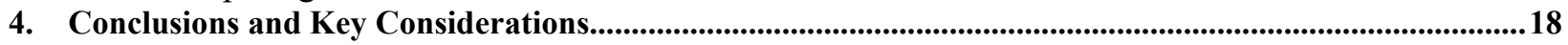

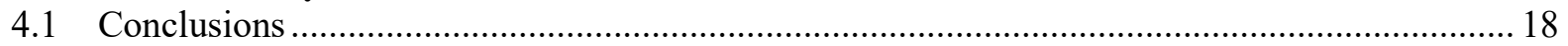

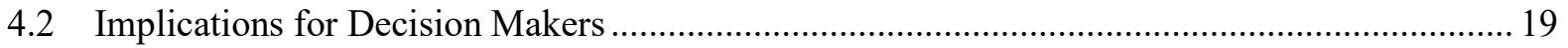

4.3 Policy Options to Address Concerns Related to the Financial Impacts of RTS ........................ 21

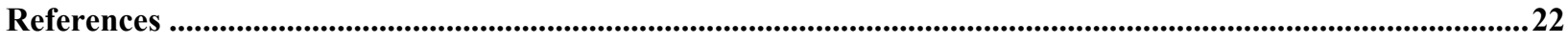

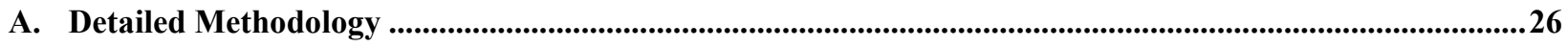

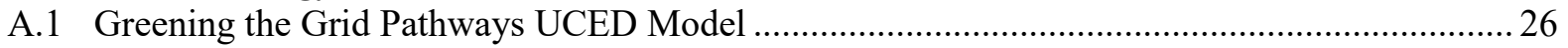

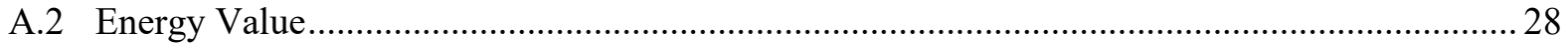

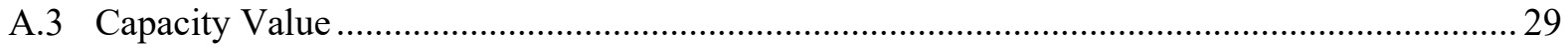

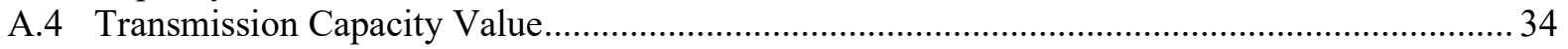

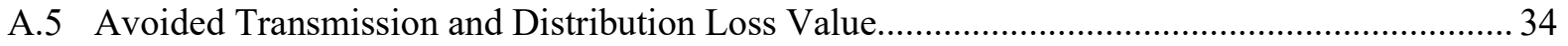

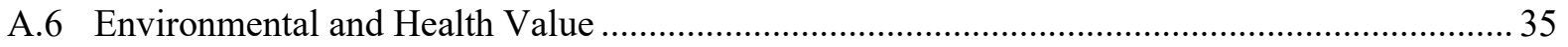

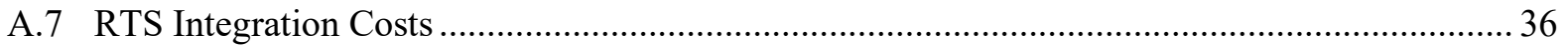

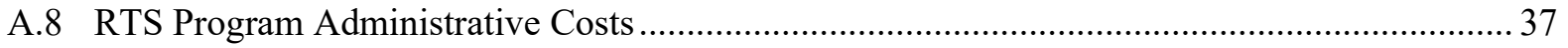

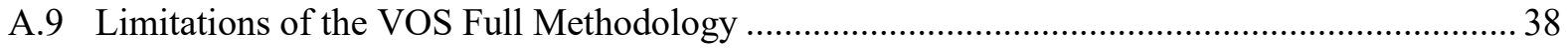

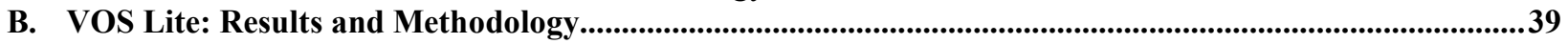

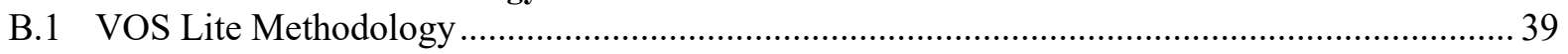

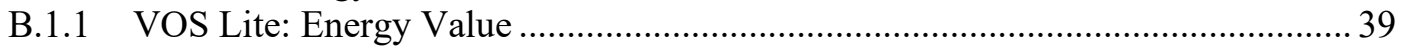

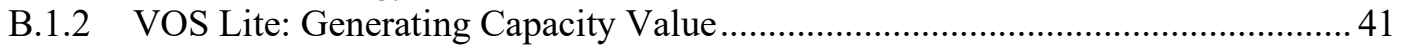

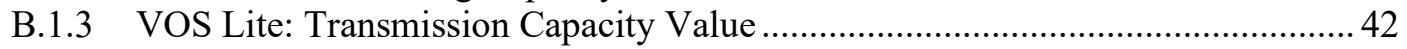

B.1.4 VOS Lite: Avoided Transmission and Distribution Loss Value ........................... 43

B.1.5 VOS Lite: Environmental and Health Value.................................................... 43

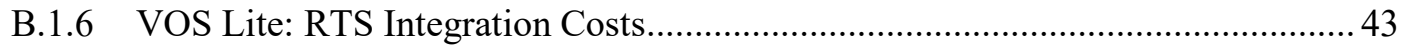

B.1.7 VOS Lite: RTS Program Administrative Costs ...................................................... 43

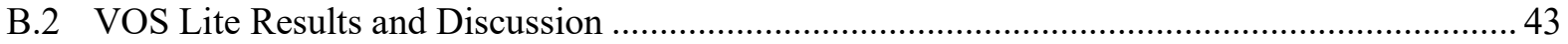




\section{List of Figures}

Figure 1. Global horizontal irradiance for Gujarat and Jharkhand. ..................................................................

Figure 2. Illustration of common costs and benefits associated with DG such as RTS ..........................................6

Figure 3. Net load and RTS generation in Gujarat for Base Case and MNRE Goals scenarios ..............................12

Figure 4. Dispatch stacks for Gujarat generating capacity on high net load day for Base Case and MNRE Goals scenarios

Figure 5. Dispatch stacks for Jharkhand generating capacity on high net load day for Base Case and MNRE

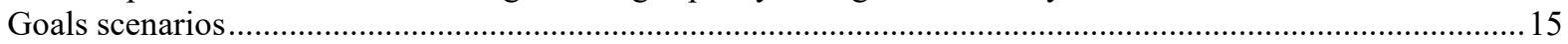

Figure 6. Net load and RTS generation in Jharkhand for Base Case and MNRE Goals scenarios............................15

Figure A- 1. Flowchart for UCED model and results .......................................................................27

Figure A- 2. Illustrative example of RTS injections during peak demand periods deferring investments in new

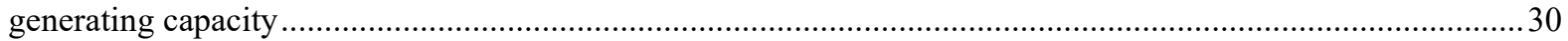

Figure B- 1. Average day-ahead IEX prices for Bid Area E1 for 2019, by season and hour. .................................40

Figure B- 2. Example of calculation of the energy value of RTS using the Dispatch Stack Method .......................4 41

\section{List of Tables}

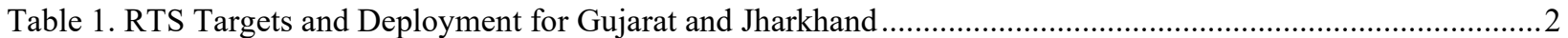

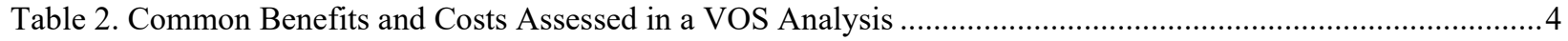

Table 3. Overview of Values Considered in the VOS Full Analysis..................................................................9

Table 4. VOS Full for State of Gujarat for Base Case and MNRE Goals Scenarios ............................................... 11

Table 5: VOS Full for State of Jharkhand for Base Case and MNRE Goals Scenarios ...........................................14

Table 6. VOS Full Results for Gujarat and Jharkhand for Base Case and MNRE Goals Scenarios......................... 16

Table 7. Comparison of VOS Values for Gujarat and Jharkhand for Base Case and MNRE Goals Scenarios

With and Without the Environmental and Health Value (rupees per kWh) ............................................. 18

Table A- 1. Generating Capacity for 2022 in UCED Model for Base Case and MNRE Goals Scenarios ................28

Table A- 2. Sources for Input Data for Calculation of the Generating Capacity Value........................................33

Table A- 3. Transmission and Distribution Losses Assumed for Scaling-Up Values ............................................35

Table A- 4. Low and High Bounds for Emission Rates and Emission Values Assumed in Analysis ........................36

Table A- 5. Assumed Values for Calculation of Program Administrative Costs for an RTS Program .................... 37

Table B- 1. Comparison of Data Sources for Inputs Into the Generating Capacity Value for VOS Full and VOS Lite Analyses

Table B- 2. VOS Results for State of Jharkhand for VOS Full and VOS Lite Analyses..... 


\section{Introduction and Background}

The Government of India has established an ambitious goal of installing $175 \mathrm{GW}$ of renewable energy by 2022; the majority of the goal comprises wind $(60 \mathrm{GW})$ and solar $(100 \mathrm{GW}) .{ }^{1}$ Of the $100-\mathrm{GW}$ solar target, $40 \mathrm{GW}$ is intended to be rooftop solar (RTS), ${ }^{2}$ with specific targets established for individual states (National Institution for Transforming India 2015). Driven by these RTS goals, individual states in India have designed solar policies and compensation mechanisms to help achieve these specific targets. Compensation mechanisms can be defined as instruments to reward the distributed generation (DG) system owner for electricity that is self-consumed and/or exported to the grid (Zinaman et al. 2017). Common compensation mechanisms such as net energy metering, net billing, and buy-all, sell-all schemes have played a critical role in enabling the growth of RTS worldwide (Denholm et al. 2014; Steward and Doris 2014). ${ }^{3}$ These policies have employed relatively simple methods to determine compensation levels for electricity exported to the distribution network by RTS systems, typically derived from existing values such as the average power purchase cost or retail tariff (Holm et al. 2019). Such approaches to RTS compensation have had the benefit of being both easily calculable by program administrators and readily understandable by customers and developers.

The dramatic growth of DG in power systems around the world and the broader evolution of the distributed energy sector has led to concerns, however, that existing compensation mechanisms may no longer sufficiently capture the net value (costs and benefits) of DG (Holm et al. 2019). Increasing sensitivity to cost-shifting between adopting and nonadopting customers has also spurred calls to review compensation mechanisms (Barbose 2017; Holm et al. 2019). ${ }^{4}$ Likewise, many stakeholders believe current compensation mechanisms are not sophisticated or cost-reflective enough of the actual value of exports to the grid to align the behavior of DG with the needs of the power system. Sufficiently estimating the net value of DG exports can help inform the design of tariffs to compensate DG system owners for exports to the power system. Furthermore, accurately capturing the (often changing) value of DG exports to the power system can ensure grid-friendly deployment and operation of DG systems, as customer compensation is more closely related to the value to the power system.

As PV system costs continue to decline and awareness of the benefits of RTS grows, RTS will likely become increasingly common in many parts of India and continue to play a larger role in the operation of the broader power system. ${ }^{5}$ To ensure that the deployment and operation of these distributed systems

\footnotetext{
${ }^{1}$ Prime Minister Modi announced at the United Nations Framework Convention for Climate Change that this target would be revised to $450 \mathrm{GW}$ of renewable energy by 2030 ; however, no official circular has yet been released for the revised target and the model used in this analysis was developed based on the current goal of $175 \mathrm{GW}$ by 2022 . Therefore, the value of solar (VOS) analysis discussed here will use the $175 \mathrm{GW}$ by 2022 goal.

${ }^{2}$ RTS here refers to solar photovoltaic (PV) systems installed behind the customer's meter. RTS installations are typically owned by individual customers, as opposed to large developers or utilities, and they are typically operated by customers to reduce the customer's utility bills (or to provide reliable power in case of a grid failure). RTS is the term commonly used in India, even though these types of systems are not necessarily located on rooftops.

${ }^{3}$ Feed-in tariffs have also been used throughout the world to stimulate the adoption of DG, but are considered to be "predetermined sell rates for electricity fed into the grid," as opposed to compensation mechanisms, as feed-in tariffs do not involve a specific metering and billing arrangement. See Zinaman et al. (2017) for more on the components of compensation mechanisms for DG.

${ }^{4}$ Cost-shifting in this context refers to the process in which utilities, facing declining volumetric sales of electricity due to some customers offsetting their consumption through DG, must increase tariffs on all customers to recover sufficient revenue to pay for the fixed costs of operating the power system, which remain relatively constant regardless of how much energy is consumed by customers.

${ }^{5}$ For up-to-date information on the deployment (cumulative and new additions) of RTS, as well as utility-scale solar PV and wind, see MNRE's Physical Progress page: https://mnre.gov.in/the-ministry/physical-progress.
} 
neither negatively impacts the operation of the power system nor the financial health of utilities (distribution companies [DISCOMs] in particular), policymakers, regulators, and stakeholders may want to more accurately understand the net costs and benefits of RTS to the power system, ratepayers, and society at large.

This report describes a value of solar (VOS) analysis framework for assessing the currently unmonetized benefits that RTS can provide to the power system. A VOS analysis can also help quantify the net impacts of RTS adoption on utility revenue sufficiency and overall value of an RTS program to the grid (see Section 1.2 for more information on VOS analyses and how they have been used in other jurisdictions). The report focuses on the VOS in two Indian states: Gujarat and Jharkhand. The two states were selected to represent two different power system contexts for the deployment of RTS (see Section 1.1 for more details on the power systems of Gujarat and Jharkhand). While the VOS framework presented in this report can be applied in many contexts and jurisdictions, the methods used and the end results can vary widely depending on local power system contexts, decision maker priorities, the timeframe of the analysis, the complexity of analysis methods used, and the granularity of available data (Holm et al. 2019). This report was prepared under the U.S. Agency for International Development (USAID)-National Renewable Energy Laboratory (NREL) Partnership, and in collaboration with the USAID Partnership to Advance Clean Energy Deployment 2.0. ${ }^{6}$

\subsection{Gujarat and Jharkhand Context}

Power system contexts can vary considerably between states in India in terms of renewable energy targets, electricity consumption patterns, policy objectives, power quality, siting and resource availability for renewable energy resources, financial health of local utilities, infrastructure availability, and compensation mechanisms. This section highlights some important distinctions between the Gujarat and Jharkhand power system contexts, which in turn can influence the potential for RTS to provide value to the power system. For instance, in states with higher peak demand periods that occur during hours of RTS operation, RTS may have a larger relative opportunity to reduce the need for new peaking capacity. Or if a given state already has a large share of existing RTS on its power system, then there may be a relatively smaller opportunity for new RTS to provide additional value to the power system. Understanding the existing or forecasted power system contexts for Gujarat and Jharkhand can help in interpreting the results for the VOS analysis and for identifying why those values might differ between states or change over time.

The state of Gujarat has high solar PV and wind renewable energy targets, which are based on forecasted energy demand, with excellent underlying resources and good siting availability in many parts of the state (Power Grid Corporation of India 2012). Jharkhand, conversely, has less available land for larger scale projects and poorer underlying solar resources (NISE 2014; NREL and USAID 2020) (Table 1 and Figure 1).

\begin{tabular}{|l|l|l|l|l|}
\hline \multicolumn{5}{|l|}{ Table 1. RTS Targets and Deployment for Gujarat and Jharkhand } \\
\hline & $\begin{array}{l}\text { Forecasted } \\
\text { 2021-22 Annual } \\
\text { Energy Demand }\end{array}$ & $\begin{array}{l}\text { MNRE } \\
\text { Target 2022 }\end{array}$ & $\begin{array}{l}\text { Cumulative RTS } \\
\text { Capacity by June 2020 }\end{array}$ & $\begin{array}{l}\text { Annual Additions of RTS } \\
\text { July 2019-June 2020 }\end{array}$ \\
\hline Gujarat & $98 \mathrm{GWh}$ & $3,200 \mathrm{MW}$ & $383 \mathrm{MW}$ & $61-120 \mathrm{MW}$ \\
\hline Jharkhand & $23 \mathrm{GWh}$ & $800 \mathrm{MW}$ & $53 \mathrm{MW}$ & $<20 \mathrm{MW}$ \\
\hline $\begin{array}{l}\text { Note: Annual capacity additions based on categories established in Bridge to India (2020). } \\
\text { Source: MNRE and GOI (2015); CEA (2018a); Bridge to India (2020) }\end{array}$ \\
\hline
\end{tabular}

${ }^{6}$ For more information on the Partnership to Advance Clean Energy program, see: https://www.pace-d.com/. 


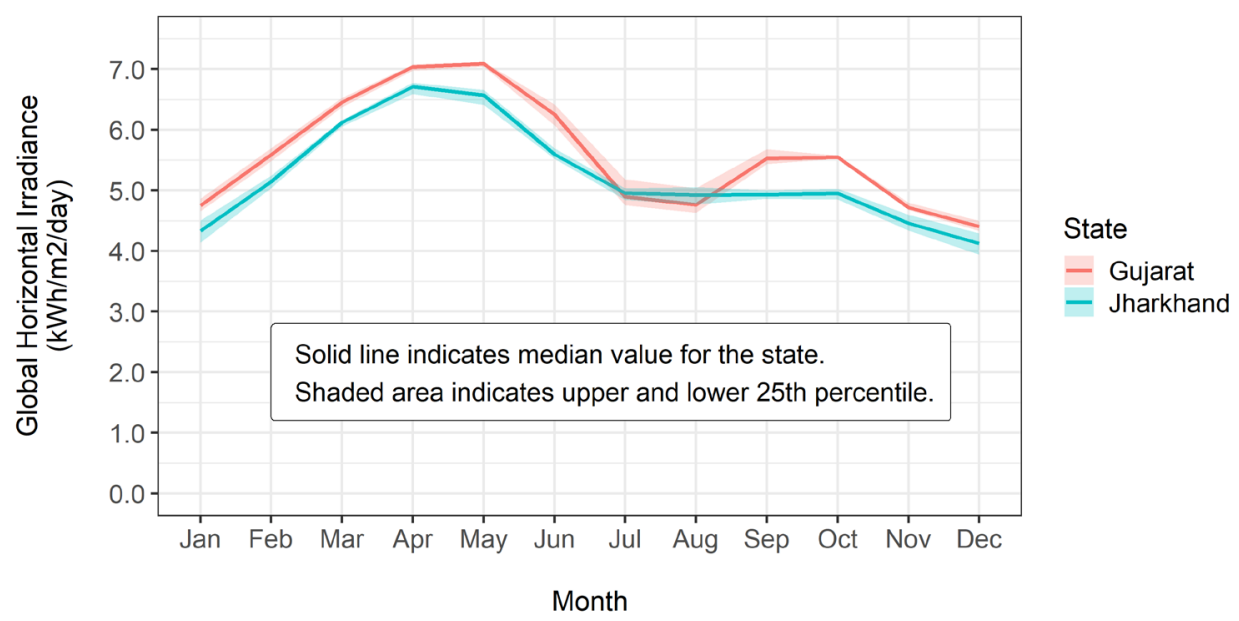

Figure 1. Global horizontal irradiance for Gujarat and Jharkhand.

Original illustration. Data source: (NREL and USAID 2020).

The overall size of the power systems in the two states also varies considerably, with Gujarat experiencing approximately five times the total and peak demand as Jharkhand. In the 2021-22 period, Gujarat is forecasted to have a total annual energy demand and peak demand of $98 \mathrm{GWh}$ and $15 \mathrm{GW}$, respectively, whereas Jharkhand is forecasted to have $23 \mathrm{GWh}$ and $3.9 \mathrm{GW}$, respectively (CEA 2018a). This difference in demand is likely driven by differences in the population and economy between the states: As of the 2011 Census, Gujarat had over 60 million residents compared to Jharkhand with approximately 33 million; and, as of 2019, Gujarat had a per capita State Domestic Product of over 150,000 rupees compared to Jharkhand with less than 55,000 rupees (Planning Commission 2013, Reserve Bank of India 2020). Gujarat also has a much more diverse generating capacity mix than Jharkhand. According to the power system model behind this study (see Sections 2 and A.1), Gujarat has significantly more wind, solar PV, hydropower, and nuclear resources than Jharkhand (Palchak et al. 2017b).

Both states feature net energy metering as the primary compensation mechanism for RTS PV exports, although Gujarat has recently created a net billing scheme as an alternative to its net energy metering scheme (Gujarat Electricity Regulatory Commission 2020). ${ }^{7}$ For net metering, any net surplus energy generated at the end of the billing cycle in Gujarat is purchased by the utility at the average pooled purchase cost, as decided by the Gujarat Energy Regulatory Commission annually (Gujarat Electricity Regulatory Commission 2016), whereas in Jharkhand, the credit is rolled over to the next billing cycle (Jharkhand State Solar Rooftop Policy 2018). For net billing in Gujarat, the sell rate at which injections from RTS to the grid are rewarded depends on the customer class of the RTS system owner (Gujarat Electricity Regulatory Commission 2020).

\footnotetext{
${ }^{7}$ Under net energy metering, customers can export energy generated by their DG system in excess of their onsite consumption to the grid. These exports receive a credit in kilowatt-hours that the customer can use to offset consumption from the grid, within the same billing cycle and often future billing cycles. The customer is billed for the net energy consumption within a billing cycle (consumption from the grid less DG exports). Under net billing, customers can still export any energy generated by their DG system in excess of onsite consumption to the grid. However, instead of receiving a kilowatt-hour credit, any exports to the grid are metered and credited at a predetermined sell rate at the moment of export. Customers must pay for net consumption from the grid at the retail rate and are compensated for net exports to the grid at the sell rate (Zinaman et al. 2017).
} 


\subsection{Introduction to VOS}

In recent years, many jurisdictions have begun reviewing or altering existing net energy metering policies. These reviews are primarily motivated in a response to the growth of RTS and corresponding changes in how the power sector is operated, particularly at the distribution level (North Carolina Clean Energy Technology Center 2019). ${ }^{8}$ As distributed assets such as RTS begin to play a more prominent role in the grid, causing reverse power flow and potentially providing valuable services to the broader power system, compensation mechanisms are coming under new scrutiny to ensure they send appropriate signals to customers and do not negatively impact nonadopting customers. One important tool for regulators, decision makers, utilities, and other stakeholders to evaluate the impacts of RTS adoption and operation on the power system and society more broadly is a VOS study. At the highest level, a VOS study provides a quantitative evidence base that can be used by decision makers to evaluate RTS policies. It can drive changes to existing policies toward more cost-reflective RTS compensation, or, alternatively, can provide confidence for the decision maker to stay the course and largely maintain existing policies.

A VOS analysis relies on a bottom-up approach to arrive at a comprehensive value for RTS based on the benefits and costs of RTS to the system. By considering certain categories of costs and benefits, it provides a more granular, data-driven approach to compensate RTS producers. While no standard methodology exists, broad categories typically considered in VOS studies include energy value, avoided transmission and distribution losses, generation capacity, transmission and distribution capacity, environmental costs and benefits, ancillary services, and other factors such as fuel price hedging and market-price suppression (Denholm et al. 2014). Some of the more common elements in the VOS are defined in Table 2. A select number of these elements are also depicted in Figure 2, including the "Lost Electricity Sales" cost, which is an important consideration for DISCOMs but is typically not assessed in VOS analyses.

Table 2. Common Benefits and Costs Assessed in a VOS Analysis

\begin{tabular}{|c|c|c|c|}
\hline Value Element & $\begin{array}{c}\text { Explored in This } \\
\text { Study? }\end{array}$ & $\begin{array}{l}\text { Cost }(C) \text { or } \\
\text { Benefit }(B) ?\end{array}$ & Description \\
\hline Energy benefits & $\begin{array}{l}\text { Yes, Energy value } \\
\quad \text { (Section A.2) }\end{array}$ & B & $\begin{array}{l}\text { Avoided fuel costs resulting from reduced need for conventional } \\
\text { electricity generation. }\end{array}$ \\
\hline $\begin{array}{l}\text { Generation } \\
\text { capacity benefits }\end{array}$ & $\begin{array}{l}\text { Yes, Generating } \\
\text { Capacity value } \\
\text { (Section A.3) }\end{array}$ & B & $\begin{array}{l}\text { In some cases, RTS can offset or delay future capital } \\
\text { expenditures (CAPEX) in generation capacity. }\end{array}$ \\
\hline $\begin{array}{l}\text { Transmission } \\
\text { and distribution } \\
\text { capacity benefits }\end{array}$ & $\begin{array}{l}\text { Transmission Capacity } \\
\text { value (Section A.4) }\end{array}$ & B & $\begin{array}{l}\text { In some cases, RTS can offset or delay future CAPEX in } \\
\text { transmission or distribution capacity. }\end{array}$ \\
\hline $\begin{array}{l}\text { Avoided line } \\
\text { losses }\end{array}$ & $\begin{array}{c}\text { Yes, Avoided } \\
\text { Transmission and } \\
\text { Distribution Loss value } \\
\text { (Section A.5) }\end{array}$ & B & $\begin{array}{l}\text { Line losses resulting from transmission and distribution of } \\
\text { electricity from generator to end customer are avoided since } \\
\text { RTS generation is consumed at or near where it is produced. } \\
\text { Note that this only applies to technical losses; nontechnical } \\
\text { losses cannot be offset by RTS as they are not a function of the } \\
\text { distance between the source of generation and load. }\end{array}$ \\
\hline
\end{tabular}

${ }^{8}$ While many jurisdictions around the world have investigated the benefits of distributed solar PV, a literature review conducted found that VOS analyses have been entirely concentrated within the United States, albeit in vastly different contexts. 
Table 2. Common Benefits and Costs Assessed in a VOS Analysis

\begin{tabular}{|c|c|c|c|}
\hline Value Element & $\begin{array}{l}\text { Explored in This } \\
\text { Study? }\end{array}$ & $\begin{array}{l}\text { Cost (C) or } \\
\text { Benefit (B)? }\end{array}$ & Description \\
\hline $\begin{array}{l}\text { Environmental } \\
\text { benefits }\end{array}$ & $\begin{array}{l}\text { Yes, Environmental \& } \\
\text { Health value (Section } \\
\text { A.6) }\end{array}$ & B & $\begin{array}{l}\text { When RTS generation offsets fossil-fuel conventional } \\
\text { generation, the environmental costs of those generation types } \\
\text { are avoided. These costs could cover damage to local } \\
\text { ecosystems through acid rain or mitigation efforts to combat } \\
\text { climate change, or compliance costs within existing policy } \\
\text { frameworks. }\end{array}$ \\
\hline Health benefits & $\begin{array}{l}\text { Yes, Environmental \& } \\
\text { Health value (Section } \\
\text { A.6) }\end{array}$ & B & $\begin{array}{l}\text { When RTS generation offsets fossil-fuel conventional } \\
\text { generation (particularly from coal), the negative health impacts } \\
\text { from that generation are also reduced. These costs could cover } \\
\text { hospitalizations due to asthma and cardiovascular disease } \\
\text { associated with exposure to pollution. }\end{array}$ \\
\hline $\begin{array}{l}\text { Ancillary service } \\
\text { benefits }\end{array}$ & No & B & $\begin{array}{l}\text { In some cases, smart inverters can provide voltage control and } \\
\text { reactive power, resulting in ancillary service value from RTS } \\
\text { generation. }\end{array}$ \\
\hline Price hedging & No & B & $\begin{array}{l}\text { RTS generation reduces exposure to fluctuating fossil fuel } \\
\text { prices tied to conventional generation and provides hedging } \\
\text { value against these risks. }\end{array}$ \\
\hline $\begin{array}{l}\text { Market price } \\
\text { suppression } \\
\text { benefit }\end{array}$ & No & B & $\begin{array}{l}\text { With increased levels of solar generation, average wholesale } \\
\text { electricity prices could be depressed during the day due the } \\
\text { merit order effect (higher marginal cost generators are avoided } \\
\text { due to zero-marginal cost solar), providing value to all electricity } \\
\text { consumers in the medium term. }\end{array}$ \\
\hline $\begin{array}{l}\text { Macro-economic } \\
\text { benefits }\end{array}$ & No & B & $\begin{array}{l}\text { The deployment of RTS in sufficient quantities can often have } \\
\text { measurable macro-economic benefits, particularly surrounding } \\
\text { the creation of jobs in industries related to manufacturing and } \\
\text { installing RTS systems. }\end{array}$ \\
\hline $\begin{array}{l}\text { Resilience } \\
\text { benefits }\end{array}$ & No & B & $\begin{array}{l}\text { RTS, in particular if combined with an energy storage system, } \\
\text { can help provide backup power to meet load during grid } \\
\text { outages. This can provide significant societal benefit if used to } \\
\text { power critical loads, such as hospitals or emergency shelters, } \\
\text { during extreme events. }\end{array}$ \\
\hline $\begin{array}{l}\text { Administrative/ } \\
\text { billing costs }\end{array}$ & $\begin{array}{l}\text { Yes, Program } \\
\text { Administrative Costs } \\
\text { (Section A.7) }\end{array}$ & C & $\begin{array}{l}\text { There may be additional costs related to setting up billing } \\
\text { systems and administrative procedures to manage the RTS } \\
\text { program. Such costs can include wages for DISCOM } \\
\text { employees to manage the program or additional time needed to } \\
\text { process billing and crediting for RTS customers. }\end{array}$ \\
\hline Integration costs & $\begin{array}{l}\text { Yes, RTS Integration } \\
\text { Costs (Section A.7) }\end{array}$ & C & $\begin{array}{l}\text { Managing RTS generation variability and uncertainty can } \\
\text { increase operations and maintenance costs for conventional } \\
\text { generation. Such costs can include increased conventional } \\
\text { power plant cycling caused by changes in net load (e.g., the } \\
\text { load minus RTS generation) in the middle of the day, or } \\
\text { distribution system reinforcement to manage voltage } \\
\text { fluctuations caused by RTS exports. }\end{array}$ \\
\hline
\end{tabular}




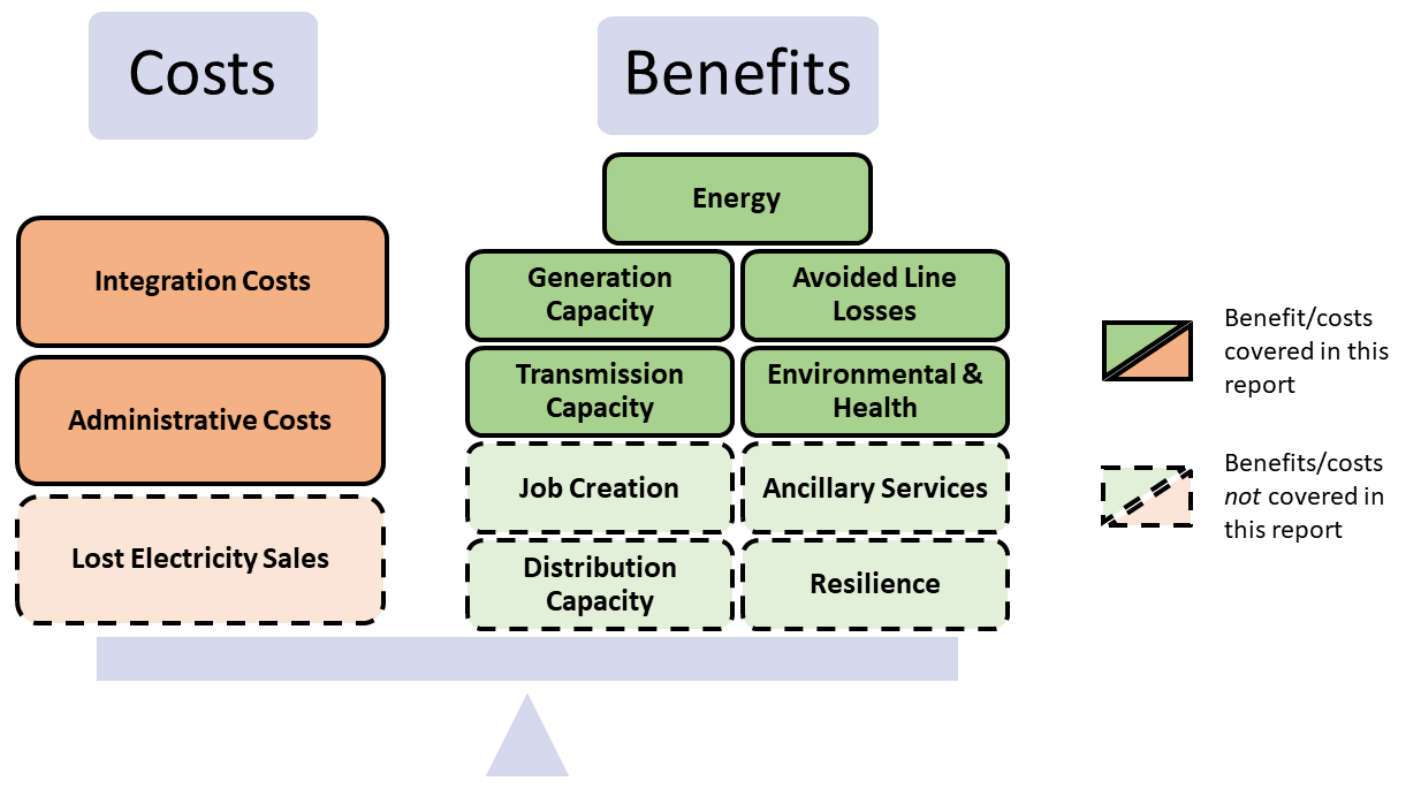

Figure 2. Illustration of common costs and benefits associated with DG such as RTS

Some of these elements of value are directly monetizable (i.e., can be reflected on utility balance sheets, such as energy value, avoided losses, generation capacity value), whereas others are externalities that are not easily monetized (e.g., health benefits from reduced particulate emissions from coal plants, macroeconomic benefits from job creation). Depending on the objective of the VOS analysis and the priorities for decision makers using its results, different sets of value elements can be included. In fact, in the formal studies that have been completed since 2012 in the United States, very few considered the exact same set of value elements. In addition to exploring different sets of values, the methodologies of VOS studies are also strongly influenced by both the availability of data as well as the institutional capacity of the stakeholders conducting the analysis (Holm et al. 2019). ${ }^{9}$ Well-staffed researchers with access to granular data and comprehensive power system models will be better suited to conduct more complex VOS analyses with more value elements considered. For stakeholders attempting to evaluate the costs and benefits of existing net metering or net billing compensation mechanisms, however, a less granular approach may be satisfactory, as well as simpler and lower cost to implement. Regardless of the methodology implemented, or the values investigated, as VOS analyses rely heavily on current understandings of power system contexts, they can typically only provide a snapshot into the VOS based on the chosen inputs to the analysis. As the underlying power system contexts change (as they are in India), the ability of RTS to offset certain costs associated with the power system will also change. Thus, VOS analyses should be performed regularly and should be used to inform near-term conditions, or, for forecasted power systems, to estimate the VOS in the future. For more information on the limitations of this methodology, see Section A.9.

In recent years, many jurisdictions have begun reviewing or altering existing net energy metering policies. These reviews are primarily motivated in a response to the growth of RTS and corresponding changes in how the power sector is operated, particularly at the distribution level (North Carolina Clean Energy

${ }^{9}$ For more information on how VOS frameworks have been employed in the United States, see Sections 4, 5, and 6 of Holm et al. (2019). Table 2 of Holm et al. (2019) in particular highlights the values that have been explored in select jurisdictions for VOS analyses. The accompanying presentation in Cory (2019) provides a similar overview of values considered in VOS analyses. 
Technology Center 2019). As distributed assets such as RTS begin to play a more prominent role in the grid, causing reverse power flow and potentially providing valuable services to the broader power system, compensation mechanisms are coming under new scrutiny to ensure they send appropriate signals to customers and do not negatively impact nonadopting customers. One important tool for regulators, decision makers, utilities, and other stakeholders to evaluate the impacts of RTS adoption and operation on the power system and society more broadly is a VOS study. At the highest level, a VOS study provides a quantitative evidence base, which can be used by decision makers to evaluate RTS policies. These studies have been used in some jurisdictions to provide a data-driven evidence base to inform more costreflective RTS compensation or, alternatively, stay the course and largely maintain existing policies.

In the United States in 2019, 22 states plus the District of Columbia were at different stages in quantifying the VOS (North Carolina Clean Energy Technology Center 2019). These studies are often motivated by legislative actions to either evaluate the current RTS program costs and benefits or to explore alternatives to current policy mechanisms to compensate RTS generation, which is currently net metering for most states (North Carolina Clean Energy Technology Center 2019). In some cases, the VOS is deemed high enough to maintain current RTS compensation policies or to make minor changes. In California in 2016, for example, regulators determined to maintain net metering with minor adjustments, including small nonbypassable volumetric energy charges in order for RTS customers to pay for services whose costs RTS cannot reduce (e.g., the Public Purpose Program Surcharge, which helps fund low-income subsidies). Moreover, new RTS customers in California are now obligated to adopt a time-of-use tariff, so that their RTS generation is valued at a rate that is more closely tied to utility costs. ${ }^{10}$ If the VOS and total costs of the RTS program is deemed higher than associated benefits, jurisdictions can choose to pivot away from net metering. For example, a VOS tariff is an alternative to current net energy metering structures and looks to compensate RTS producers at a level that corresponds to the assessed value that solar provides to the electricity system. In this case, the compensation of RTS is no longer tied to the customer's underlying retail tariff but rather to the broader power market context.

The state of New York, for example, has developed a Value of Distributed Energy Resources (VDER) framework to eventually replace net energy metering tariffs. VDER compensates customers by capturing several different values including energy, environment, generating capacity, distribution and transmission capacity, and distribution and transmission losses. The compensation customers receive for energy exports varies across utility territories (and sometimes within the same territory) as well as over time, depending on when distributed energy resource (DER) exports are most valuable to the broader power system. The VDER framework has been adjusted several times since its inception in order to balance investors' need for revenue stability and certainty with the dynamic value of RTS exports to the power system (NYPSC 2019). ${ }^{11}$

\footnotetext{
${ }^{10}$ For a more detailed explanation of how time-of-use tariffs can align customer costs, RTS compensation and power system needs, please see Section 4.2.1 of Zinaman et al. (2020).

${ }^{11}$ New York has taken several other steps toward more cost-reflective compensation mechanisms and reducing costshifting, such as offering time-of-use tariffs and developing Customer Benefit Contribution charges $(\$$ per $\mathrm{kW}$ DC per month) for RTS customers, as a part of its broader Reforming the Energy Vision Initiative (NYPSC 2020). These charges are meant to help recover, although not entirely, the fixed costs of operating the power system that might otherwise need to be recovered through increased retail tariffs on all customers. See Footnote 4 for additional information.
} 


\section{New York's VDER Framework}

New York's VDER framework seeks to compensate customers' exports at a rate equivalent to the value those exports provide to the power system. VDER seeks to balance the need for fluctuating compensation to match the changing value of the exports against the need for stability to provide a measure of investor confidence that investments in DER like RTS will be economically viable over the asset's life. A selection of values from the VDER "value stack" are detailed below:

The energy value is based on the day-ahead wholesale market prices of the regional transmission operator's load zones in which the DER is located. These prices, and therefore the compensation rate, change every hour, providing highly reflective, if uncertain, signals to the DER.

The capacity value is based on averaged capacity auction market values and are fixed 1 year at a time. Under one option of VDER, the capacity value can only be earned for exports during certain hours of the year when the power system's peak demand is expected.

The demand reduction value is a measure of the ability of DERs to reduce the need for investments in transmission and distribution infrastructure by reducing demand during certain hours of the year when such infrastructure may be reaching its capacity limits. The demand reduction value is calculated by each major utility in New York based on historic cost information of past investments, and the hours in which the DER can earn the demand reduction value are determined by the utilities based on system peak demand periods. The demand reduction value compensation rate changes regularly for new systems but is fixed for a given DER system for 25 years to provide a measure of investor certainty.

The environmental value is based on the higher of the Renewable Energy Certificate prices (which are used to determine compliance with state-mandated renewable portfolio obligations) or a calculated Social Cost of Carbon. The level of compensation for the environmental value is likewise fixed for a given DER system for 25 years to provide additional investor certainty.

Together, these values help align the deployment and operation of DER with the broader needs of the power system.

Sources: (NYPSC 2017, NYPSC 2019) 


\section{VOS Analysis: Methodology Overview}

The VOS analysis for the states of Jharkhand and Gujarat (referred to throughout the report as VOS Full) relied on a combination of publicly available data and a unit commitment and economic dispatch (UCED) model to capture how exports from RTS could feasibly impact the operation of the power system. The UCED model was developed as part of the Greening the Grid initiative with significant stakeholder feedback, and it models the Indian power system in high levels of granularity, with additional granularity for specific Indian states (Palchak et al. 2017a; Palchak et al. 2017b). Five values were explored, chosen based on the availability of data and methodology. These values, while capturing a large portion of the value of RTS in each state, are not exhaustive of the benefits or costs that RTS can provide or induce. Table 3 provides an overview of the values and costs considered. A more in-depth discussion on the UCED model and value methodologies employed can be found in Appendix A. Limitations of the analysis' methodology can be found in Section A.9.

\begin{tabular}{|c|c|}
\hline Value or Cost & Explanation of Methodology \\
\hline $\begin{array}{l}\text { Energy Value (Section } \\
\text { A.2) }\end{array}$ & $\begin{array}{l}\text { The UCED model generates a metric, the short-run marginal cost (SRMC), that } \\
\text { represents the economic value of reducing generation from a given unit. The } \\
\text { highest SRMC from generating units in each hour was used as the energy value. }\end{array}$ \\
\hline $\begin{array}{l}\text { Generating Capacity } \\
\text { Value (Section A.3) }\end{array}$ & $\begin{array}{l}\text { Net load patterns from the UCED were used to determine the fraction of RTS } \\
\text { capacity that could be relied upon to meet peak demand. This was combined with } \\
\text { assumptions on the costs of the next new generating capacity addition. }\end{array}$ \\
\hline $\begin{array}{l}\text { Transmission Capacity } \\
\text { Value (Section A.4) }\end{array}$ & $\begin{array}{l}\text { The UCED model generates information on energy prices at specific nodes within } \\
\text { the power system of each state. The transmission capacity value was taken to be } \\
\text { the difference in these nodal prices given assumptions about the node at which } \\
\text { RTS would inject energy. }\end{array}$ \\
\hline $\begin{array}{l}\text { Avoided Transmission and } \\
\text { Distribution Loss Value } \\
\text { (Section A.5) }\end{array}$ & $\begin{array}{l}\text { The state average distribution and transmission losses were used to scale up the } \\
\text { other four values explored as less generation and capacity would be needed from } \\
\text { local RTS than from distant centralized units. }\end{array}$ \\
\hline $\begin{array}{l}\text { Environmental \& Health } \\
\text { Value (Section A.6) }\end{array}$ & $\begin{array}{l}\text { Assumptions of the emissions rate of the power plants that would be turned down } \\
\text { in response to RTS were combined with assumptions of the monetized } \\
\text { environmental and health benefits of reduced emissions, yielding benefits in terms } \\
\text { of RTS generation. }\end{array}$ \\
\hline $\begin{array}{l}\text { RTS Integration Costs } \\
\text { (Section A.7) }\end{array}$ & $\begin{array}{l}\text { Integration costs for Gujarat and Jharkhand were converted from commonly } \\
\text { accepted average integration costs in the United States. Due to differences in costs } \\
\text { of labor, which are a driver of integration costs, integration costs for the Indian } \\
\text { states were assumed to be a fraction of those in the United States. }\end{array}$ \\
\hline $\begin{array}{l}\text { RTS Program } \\
\text { Administrative Costs } \\
\text { (Section A.8) }\end{array}$ & $\begin{array}{l}\text { Initial RTS program costs were assumed to be fully recovered by the year of the } \\
\text { study's focus. Recurring (annual) program costs were included and were based on } \\
\text { discussion with NREL analysts and in-country USAID partner TetraTech. }\end{array}$ \\
\hline
\end{tabular}


Two scenarios were explored for the VOS Full analysis for Jharkhand and Gujarat in the UCED model, a Base Case and MNRE Goals. In both scenarios, the same underlying load patterns and operational characteristics of the power system (e.g., ramp rates of the generation fleet, transmission capacity) were assumed, based on conversations with Indian power system stakeholders during the creation of the UCED model. Additionally, the same thermal generating capacity was assumed in both scenarios, based on the National Electricity Plan and conversations with stakeholders. Finally, both scenarios model the Indian power system for the year 2022 (based on assumed load patterns and generating and transmission capacity). In the Base Case scenario, similar levels of solar PV (RTS and utility-scale) and wind generating capacity as today (2020) are assumed. In the MNRE Goals scenario, significant solar PV and wind capacity additions to achieve the state-level MNRE targets for renewable deployment are assumed. Figure A- 1 in Section A.1 provides a high-level overview of the process of using UCED models and assumptions on the power system to model various metrics in high granularity on the operation of the power system, which can be used for analyses such as VOS studies.

In addition to the UCED-based VOS Full analysis for Jharkhand and Gujarat, a second VOS analysis (referred to in this report as VOS Lite) was also performed for the state of Jharkhand using a simplified Excel-based model and publicly available data. The results in the rest of this report, unless otherwise noted, refer to VOS Full results. Information on the methodology used and values explored for the VOS Full analysis can be found in Appendix A. Results for the state of Jharkhand from the VOS Lite analysis can be found in Appendix B. An explanation for the motivation of the VOS Lite study is provided in the text box below.

\section{Motivations for a Separate VOS Lite Analysis}

The VOS Full and VOS Lite analyses attempt to provide an estimate of the value RTS can provide to the power system and society. The VOS Full provides highly granular estimates (geospatially and temporally) of this value and makes it possible to estimate several potential sources of value from RTS. Furthermore, changes to the power system (such as between scenarios) are reflected in more granular detail in the VOS Full model than could be achieved with the VOS Lite model. For instance, myriad effects from additional wind and solar PV capacity (including changes to how coal plants must ramp up and down or how transmission constraints may change) are captured in the UCED model. Thus, the VOS Full analysis is a more thorough approach that captures more values in higher granularity and can be adjusted to reflect various scenarios and future cases while maintaining a high degree of accuracy.

While the use of the UCED model provides accuracy and granularity, it also makes the VOS Full analysis more opaque, as stakeholders are not able to see all of the assumptions in the UCED model. The UCED model is also complex, and the metrics it produces, while thorough, may be challenging to interpret to stakeholders unfamiliar with UCED models. The VOS Lite approach uses publicly available data and a transparent Excel model and is more interpretable to stakeholders. As the Excel model is open source, other jurisdictions can easily change input data to match their local context without having to rerun a UCED model to output results. That said, the VOS Lite approach requires historical data and may not be appropriate for examining future scenarios, in particular if the power system is expected to undergo significant changes to demand patterns or generating capacity mixes, as could be expected in India.

The two approaches represent a tradeoff in granularity, forecasting and scenario-building capabilities on the one hand and interpretability, replicability, and ease of use on the other. 


\section{VOS Analysis Results: VOS Full}

The following subsections detail the results from the VOS Full analysis for Gujarat and Jharkhand. The states are dealt with separately in Section 3.1 and 3.2 for Gujarat and Jharkhand, respectively, before being compared across the states in Section 3.3.

\subsection{Gujarat Results}

The final results for the state of Gujarat from the VOS Full analysis for the Base Case and MNRE Goals scenarios are shown in Table 4. In the Base Case scenario, the driving RTS values were the Environmental and Health and Energy values and, to a lesser extent, the Generating Capacity value, with negligible contributions from the Transmission Capacity value. In the MNRE Goals scenario, both the Energy and Generating Capacity value decline relative to the Base Case. The Energy value decreased approximately $7 \%$ and the Generating Capacity decreased by over $99 \%$.

Table 4. VOS Full for State of Gujarat for Base Case and MNRE Goals Scenarios

\begin{tabular}{|c|c|c|c|}
\hline & & \multicolumn{2}{|c|}{ Rooftop Solar (RTS) Value (INR/MWh) } \\
\hline & & VOS Full & VOS Full \\
\hline & & Base Case & MNRE Goals \\
\hline Energy & Avoided Energy Cost & $4,246.88$ & $3,955.73$ \\
\hline Generation Capacity & Avoided Capital Investment / Fixed O\&M & 683.80 & 1.47 \\
\hline Transmission Capacity & Avoided Transmission Capacity & 4.27 & 5.21 \\
\hline \multirow{4}{*}{$\begin{array}{c}\text { Environmental \& } \\
\text { Health }\end{array}$} & Avoided NOx Cost & \multicolumn{2}{|c|}{$1,975.69-2,392.37$} \\
\hline & Avoided SO2 Cost & \multicolumn{2}{|c|}{$2,166.09-2,809.04$} \\
\hline & Avoided CO2 Cost & \multicolumn{2}{|c|}{$1,065.10-1,640.17$} \\
\hline & Avoided PPM Cost & \multicolumn{2}{|c|}{$5.39-141.77$} \\
\hline \multirow{3}{*}{ Costs } & Solar Integration Costs & \multicolumn{2}{|c|}{-90.00} \\
\hline & Program Administration Costs & \multicolumn{2}{|c|}{-53.69} \\
\hline & & $10,003.53-11,774.62$ & $9,030.99-10,802.08$ \\
\hline
\end{tabular}

The Generating Capacity value is driven by: (1) the alignment of when RTS generates power and when the bulk power system experience peak net demand; and (2) the cost of the next generation capacity addition. ${ }^{12}$ The costs of the next generating unit and the hours in which RTS was generating were assumed to be the same between the two scenarios. Therefore, the drastic drop in the Generating Capacity value is driven largely by changes in when the system's peak net demand occurs. Figure 3 shows how the peak net load changes dramatically between the two scenarios as additional solar and wind generating capacity are added to the power system. The net load is relatively flat in the Base Case rainy season, and

${ }^{12}$ Peak net demand is used, rather than peak demand, as net demand represents the total demand less VRE generation, or the demand that must be met with conventional generating resources. For more information, see Section A.3. 
has mid-day peaks for the Base Case the spring, summer, and winter. Late-day peaks in the average net load appear in the winter and spring, as well as the fall. The yellow bars in the background represent RTS generation in the two scenarios, with darker shades corresponding to higher levels of RTS generation, which has a greater impact on the net load (see note below figure).

As can be seen in Figure 3, in the Base Case scenario, hours of peak net demand can reasonably be expected to occur during hours of RTS generation. This is a result of relatively low overall penetration of the RTS in Gujarat. In the MNRE Goals scenario, however, the peak net demand periods are more likely to occur outside the hours of RTS generation. This is because RTS and utility-scale generation are highly coincident (or, occur at the same time) and with enough solar generating capacity installed, the periods of net peak demand will shift to occur outside the hours of solar generation. The result is that the summer and rainy seasons have peak net load early in the morning and late in the evening. The spring, autumn, and winter realize a peak load in the evening as the RTS and larger solar systems are ramping down production. In the state of California in the United States, the effect of coincident solar PV generation on the shape of net load is called "the duck curve," with low net load in the middle of the day followed by large evening ramps. This shape tells a story and anticipates the need for flexible power sources and flexible load that can accommodate larger load shifts and quicker ramping than in the Base Case (CAISO 2016; CAISO 2020). This can be addressed with energy storage to shift some solar generation to different hours of the day or with demand response, to shift when load occurs; however, without these interventions, the Generating Capacity value will tend to decrease with increasing levels of RTS (or utility-scale solar PV) penetration.

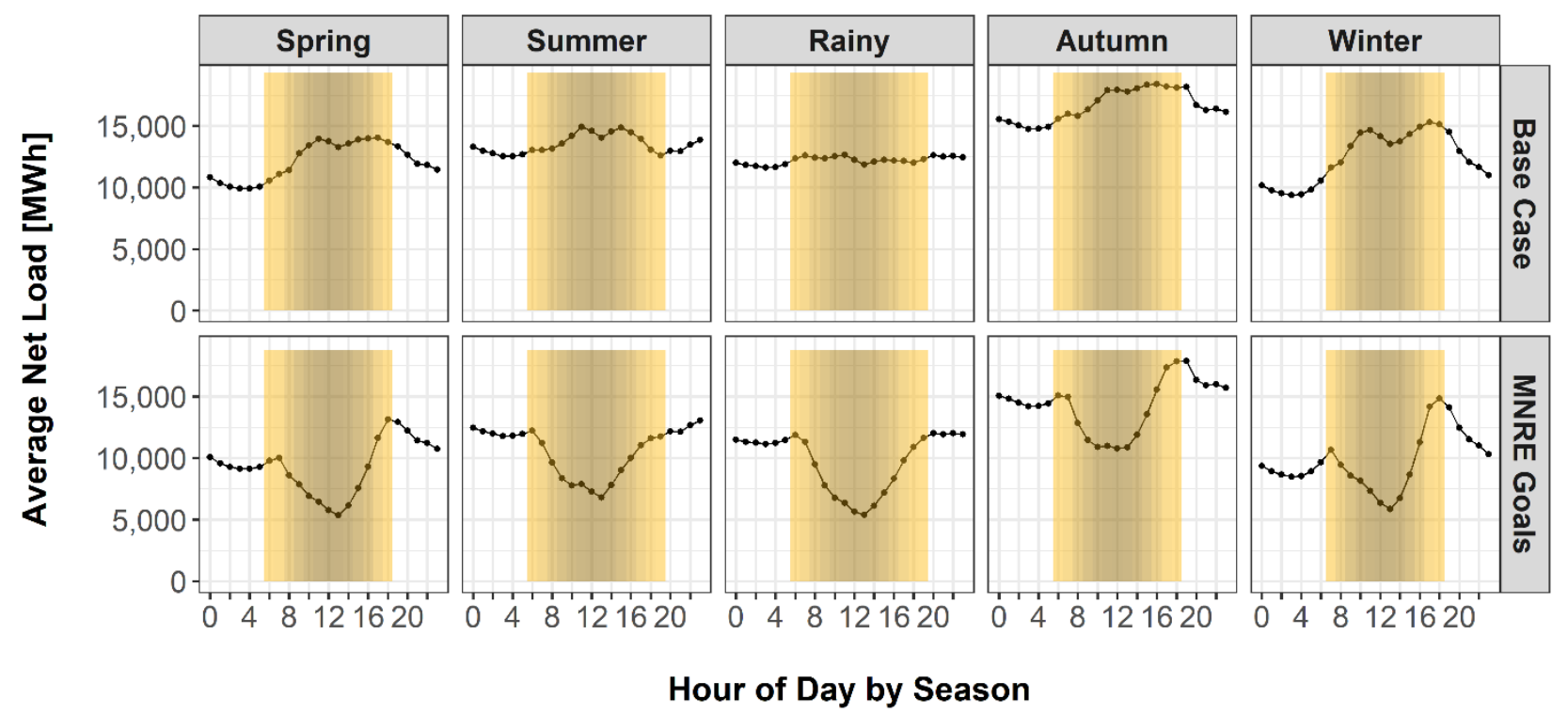

Figure 3. Net load and RTS generation in Gujarat for Base Case and MNRE Goals scenarios

Note: The colored bars in the background represent the average RTS generation in the state for each month and hour, relative to the maximum RTS generation throughout the year for each scenario. Darker bars represent hours in which the average RTS generation was closer to the annual maximum for the scenario. The mapping of months to specific seasons was determined based on conventions developed in Palchak et al. (2017) in consultation with a number of in-country stakeholders from varying viewpoints: Spring includes February and March; Summer includes April, May, and June; Rainy includes July, August, and September; Autumn includes October and November; and Winter includes December and January.

Although the Generating Capacity value decline was the largest percentage decline and the largest overall net impact to the VOS, the Energy value also experienced a noticeable decline. As with the Generating 
Capacity value, this decline is driven by the increased presence of variable generating resources in the MNRE Goals scenario. The Energy value is driven by the SRMC metric that measures the costs avoided by reducing generation from the most expensive generator online during each hour of RTS exports (see Section A.2). Variable renewable energy (VRE) generators, such as solar PV and wind, tend to reduce the cost of meeting demand, as they offset more expensive generation when they are available. Thus, higher levels of VRE penetration tend to lead to lower overall energy prices, which in turn reduces the ability of RTS to further save utilities and customers money.

In Figure 4, the generators in the state of Gujarat are ordered from left to right, according to their SRMC, which represents the cost of generating an additional unit of power from them for a day of high net load at 12 p.m. Each bar represents a different generator, and the width of each bar corresponds to its installed capacity, while its height corresponds to its SRMC. In general, generators like solar PV (utility-scale or RTS), wind, and hydro have significantly lower operating costs than coal or natural gas, as they do not have associated fuel costs. Typically, as demand increases, more expensive generators are dispatched to supply energy (moving to the right along the graph). The additional solar PV and wind generators in the MNRE Goals scenario (left side of the lower graph) shifts the more expensive generators to the right, which corresponds to lower fuel costs to meet the same amount of demand. ${ }^{13}$ As solar PV generation is highly coincident, the hours during which RTS is generating should also correspond to generation from utility-scale $\mathrm{PV}$, and therefore lower average costs of producing electricity, leading to a lower overall Energy value.

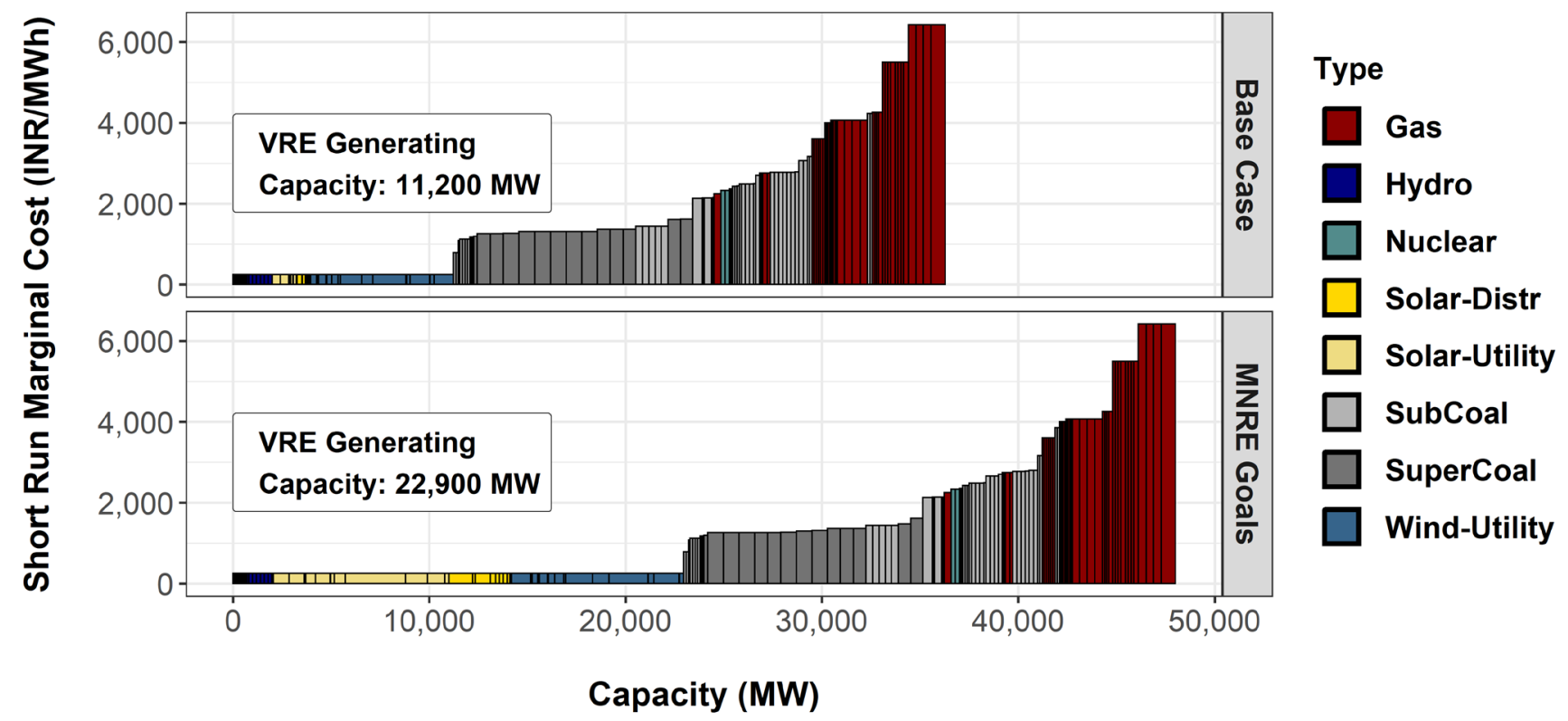

\section{Figure 4. Dispatch stacks for Gujarat generating capacity on high net load day for Base Case and MNRE Goals scenarios}

\footnotetext{
${ }^{13}$ In the case of VRE generators like solar PV and wind, the availability of underlying resources (solar radiation or wind) dictates which generators will be dispatched to meet demand, and therefore the costs of meeting demand in any given hour. On average, however, one can expect that higher levels of solar PV and wind should lower the costs of supplying energy as cheaper generators are dispatched more frequently. This also ignores constraints on thermal generating fleets, such as minimum stable levels or startup costs, which are fully captured in the UCED model. The graphs here are only meant to illustrate how increased solar PV and wind capacity might explain lower energy costs, and therefore lower overall Energy values from RTS.
} 
In both scenarios, the Environmental and Health value was a strong driver for the overall VOS exports. The Environmental and Health value did not change between scenarios because RTS exports were always assumed to offset coal generation (see Section A.6). The variation in the Environmental and Health value is driven by ranges in the underlying assumptions for the rate of emissions (ton of emission/ $\mathrm{MWh}$ ) for the average coal plant, as well as ranges in the overall value of reducing those emissions (INR/ton of emission).

\subsection{Jharkhand Results}

The final results for the state of Jharkhand from the VOS Full analysis for the Base Case and MNRE Goals scenarios are shown in Table 5. In the Base Case scenario, the driving RTS values were the Environmental and Health and Energy values, with negligible contributions from the Generating Capacity and Transmission Capacity values. In the MNRE Goals scenario, both the Energy and Generating Capacity value marginally decline relative to the Base Case.

Table 5: VOS Full for State of Jharkhand for Base Case and MNRE Goals Scenarios

\begin{tabular}{|c|c|c|c|}
\hline & & \multicolumn{2}{|c|}{ Rooftop Solar (RTS) Value (INR/MWh) } \\
\hline & & \multirow{2}{*}{ Base Case } & \multirow{2}{*}{$\frac{\text { VOS Full }}{\text { MNRE Goals }}$} \\
\hline & & & \\
\hline Energy & Avoided Energy Cost & $2,461.27$ & $2,412.13$ \\
\hline Generation Capacity & Avoided Capital Investment / Fixed O\&M & 14.61 & 0.19 \\
\hline Transmission Capacity & Avoided Transmission Capacity & 8.01 & 12.97 \\
\hline \multirow{4}{*}{$\begin{array}{c}\text { Environmental \& } \\
\text { Health }\end{array}$} & Avoided NOx Cost & \multicolumn{2}{|c|}{$1,975.69-2,392.37$} \\
\hline & Avoided SO2 Cost & \multicolumn{2}{|c|}{$2,166.09-2,809.04$} \\
\hline & Avoided CO2 Cost & \multicolumn{2}{|c|}{$1,065.10-1,640.17$} \\
\hline & Avoided PPM Cost & \multicolumn{2}{|c|}{$5.39-141.77$} \\
\hline \multirow{3}{*}{ Costs } & Solar Integration Costs & \multicolumn{2}{|c|}{-90.00} \\
\hline & Program Administration Costs & \multicolumn{2}{|c|}{-55.75} \\
\hline & & $7,550.40-9,321.49$ & $7,491.81-9,262.90$ \\
\hline
\end{tabular}

The results from both the Base Case and MNRE Goals scenarios are similar between the two scenarios, driven by the relatively little solar PV (utility-scale and RTS) and wind that are added to the state of Jharkhand in the MNRE Goals scenario. As the load and conventional generating capacity are the same between the two scenarios, the marginal increases in RTS and utility-scale wind and solar mean that the state's power system does not dramatically change between the two scenarios (although considerable changes in other Indian states between scenarios are captured in the model).

Figure 5 illustrates why the Energy value remains stable between the two scenarios in more detail. As explained for Figure 4 in Section 3.1, the chart compares the capacities and SRMC for the generating fleet in Jharkhand (see Section A.2 for more information on the SRMC). Typically, as demand increases, more expensive generators are dispatched to supply energy (moving to the right along the graph). In Jharkhand, however, relatively little new renewable energy generating capacity is added between the scenarios (an increase of approximately $700 \mathrm{MW}$ ) and the generation fleet remains dominated by coal. This leads to relatively stable SRMCs and little change in the Energy value. 


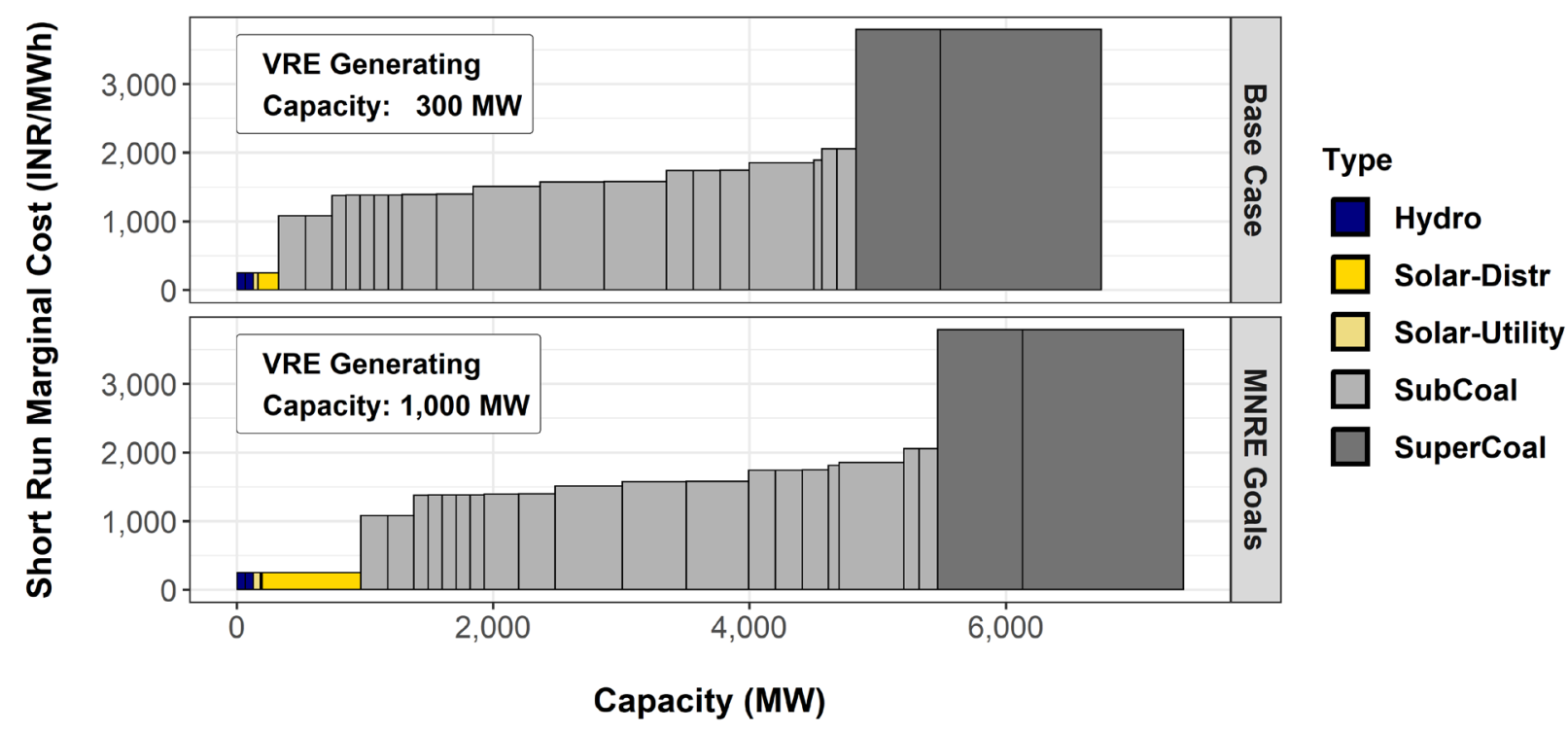

Figure 5. Dispatch stacks for Jharkhand generating capacity on high net load day for Base Case and MNRE Goals scenarios

The low Generating Capacity value is driven primarily by a mismatch between Jharkhand's net load and RTS generating patterns: If RTS cannot be relied upon to offset the need for investments in generating capacity, which are driven by peak net demand, then its Generating Capacity value will be low (see Section A.3). Figure 6 shows the overlap of the average net demand in Jharkhand (black lines and points) by season and hour of the day, as well as RTS generating hours (yellow bars). As shown, the average net peak demand consistently occurs outside the prime RTS generating hours in all seasons. This indicates a poor ability of any solar PV to offset the need for investments in new generating capacity.
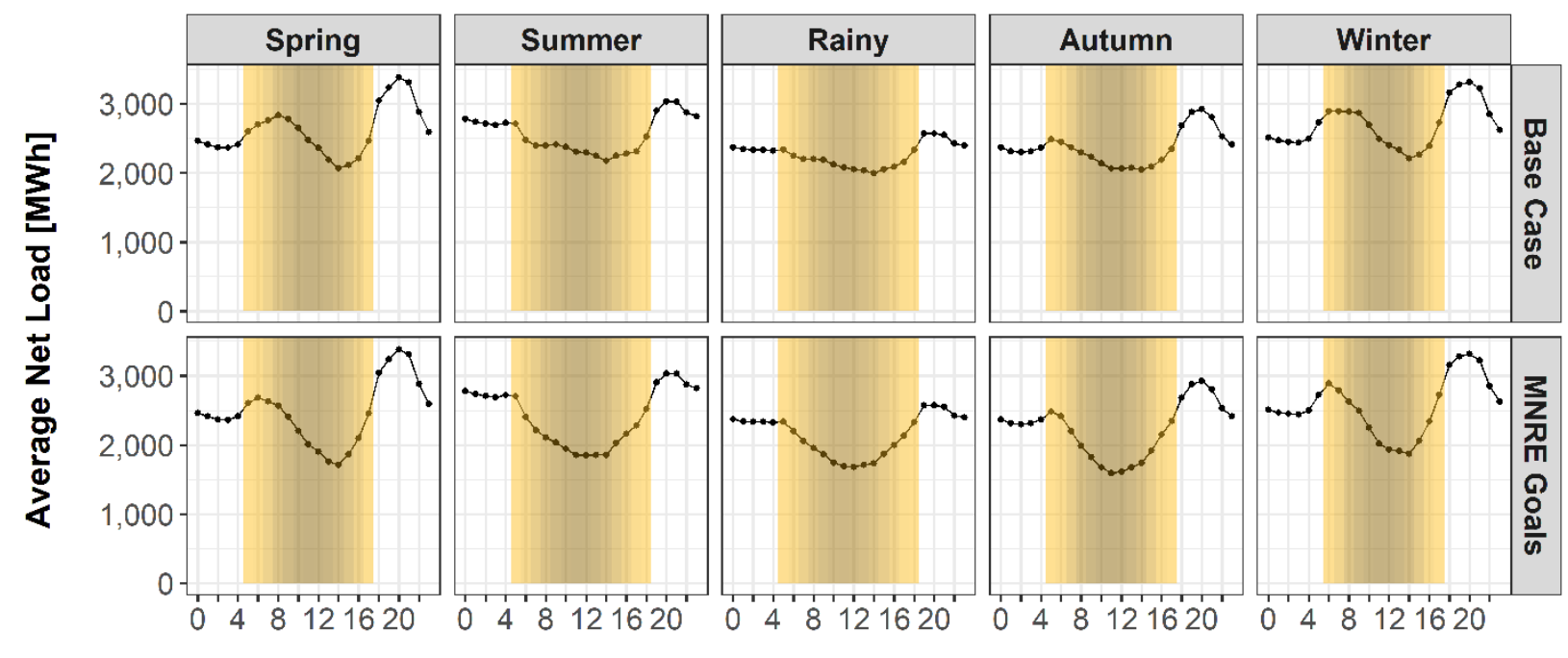

Hour of Day by Season

Figure 6. Net load and RTS generation in Jharkhand for Base Case and MNRE Goals scenarios

Note: for an explanation of the colored bars in the background, as well as of the seasons, see the note under Figure 3. 


\subsection{Comparing Results}

The power system contexts for Gujarat and Jharkhand are considerably different. Gujarat is a significantly larger and more diverse power system with more existing VRE generation. Gujarat also has better solar resources than Jharkhand. Furthermore, Gujarat is expected to add significantly more VRE generation by 2022 under the MNRE targets. As VOS is strongly influenced by local power system conditions and solar resource availability, it is unsurprising that the results for many of the values in the VOS Full analysis for the two states would also be quite different. Table 6 compares the VOS Full results for both Gujarat and Jharkhand across both the Base Case and MNRE Goals scenarios.

Table 6. VOS Full Results for Gujarat and Jharkhand for Base Case and MNRE Goals Scenarios

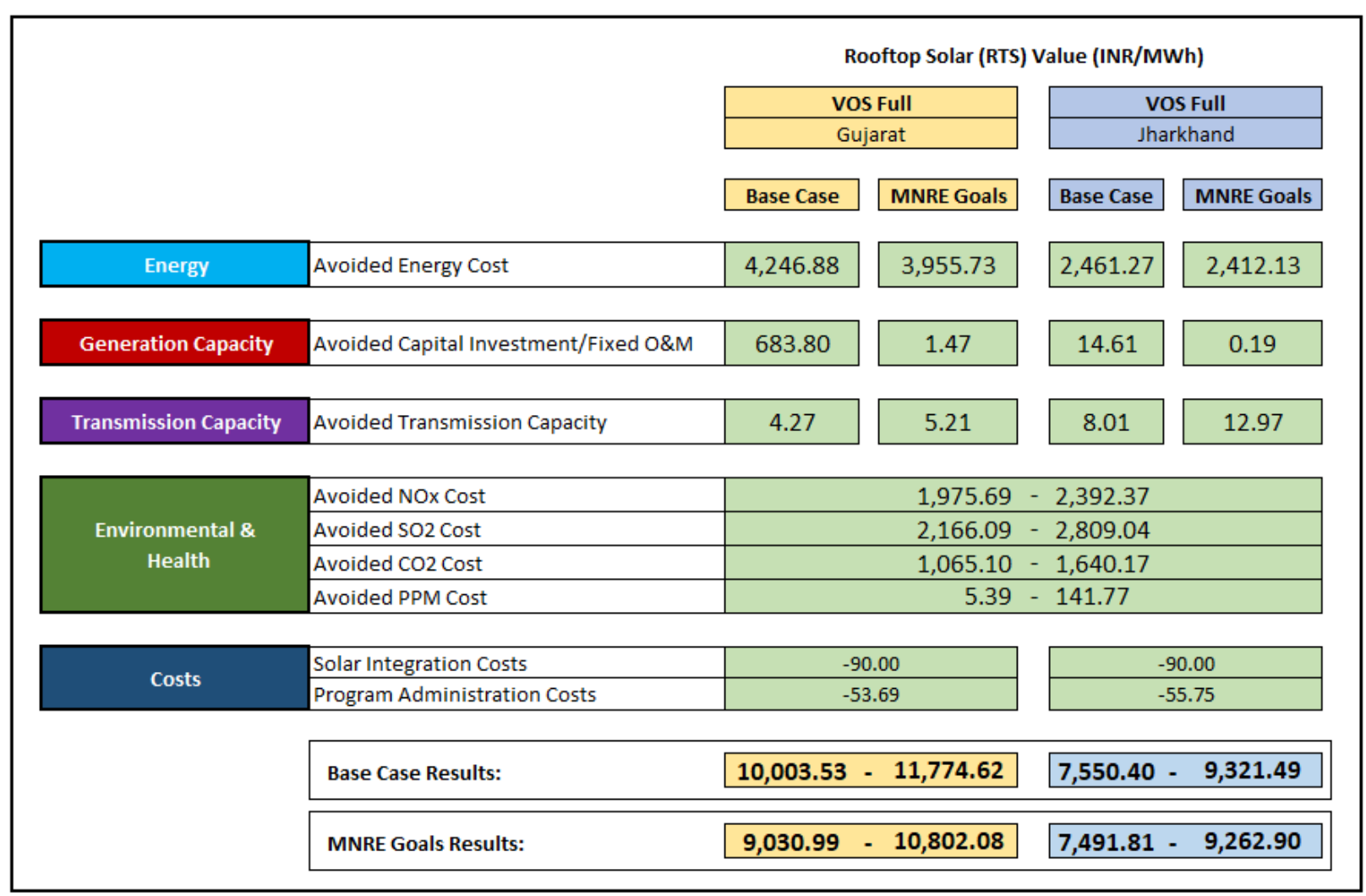

The magnitude of the Energy value in Gujarat is significantly higher than in Jharkhand. This is likely driven by the fact that many of Gujarat's generators are more expensive than those in Jharkhand. Jharkhand has plentiful access to coal reserves and can therefore generate electricity with coal more cheaply than Gujarat. Furthermore, Gujarat has significantly more demand and more generating capacity diversity, which offers solar PV the chance to offset more expensive generators such as natural gas. This creates larger opportunities for RTS to reduce energy costs by offsetting centralized generation. Another factor that drives Gujarat's Energy value higher than Jharkhand's is the more diverse generating mix, which can be seen by comparing Figure 4 and Figure 5. The Energy Value between the two scenarios in each state also declines at different rates (a 7\% decline in Gujarat and a $\sim 2 \%$ decline in Jharkhand). The considerable increase in VRE generating capacity in Gujarat between the two scenarios drives the reduction in the Energy value, because expensive conventional generators are less likely to be on the margin during periods of RTS generation, reducing the opportunity for RTS to further reduce energy costs. Conversely, Jharkhand's energy costs are already low, and a comparatively smaller amount of new VRE capacity is added between the two scenarios. This means there is less opportunity to reduce energy prices and that the opportunity does not drastically change. 
The difference in the magnitudes of the Generating Capacity values for the Base Case is also noticeable between the two states. In Gujarat for the Base Case, there is an opportunity for RTS to reduce peak net demand (Figure 3), which drives a higher RTS value. In Jharkhand, most of the peak net demand occurs outside normal RTS generating hours (Figure 6), which means RTS alone has little opportunity to reduce the need for new generating capacity investments. Additionally, the Generating Capacity value in Jharkhand is already negligible, and does not dramatically change between scenarios simply because the additional VRE generating capacity does not drastically impact when the peak net demand occurs. In Gujarat, however, the Generating Capacity is reduced by over $99 \%$. This is because the significant additions of VRE generating capacity between the scenarios shifts the peak net demand periods from within RTS generating hours to outside of RTS generating hours, diminishing RTS' ability to reduce peak net demand.

Although the magnitude of the Energy and Generating Capacity values for the two states were significantly different, both experienced declines between the Base Case and MNRE Goals, albeit at different rates. This indicates that in both power system contexts there is declining marginal value (for energy and generating capacity) from increasing penetrations of RTS. In other words, there is a limited ability of RTS alone to reduce energy prices and reduce the need for new generating capacity as the power systems become saturated with RTS and utility-scale solar PV capacity.

Conversely, for both states and scenarios, the Environmental and Health value was significant in magnitude. The static nature of the value is primarily an artefact of the analysis: the value was assumed to be the product of the average emissions rate across the set of coal generating units. Despite attempts to get more clarity on which specific units are generating during which hours and the associated emissions of those specific units, so as to understand which emissions could be avoided, access to such data was unavailable. Therefore, the analysis used a simplifying assumption that using a range of emission values would capture the potential reduction in monetary value given emissions reductions from coal plants. The range in the Environmental and Health value is driven by ranges in the assumptions for the emissions rate and emissions value. The magnitude of the Environmental and Health value indicates that there is a significant benefit associated with offsetting conventional generation with RTS injections that accrues to society at large, although this benefit does not accrue directly to the DISCOM. Given more accurate emissions data for each power plant, a more specific analysis of emissions reductions could be performed.

For both Gujarat and Jharkhand, and in both scenarios, the Transmission Capacity value was insignificant. This indicates that RTS is unable to offset the need for new transmission capacity or reduce congestion significantly, either because there is little congestion or need for new transmission capacity to reduce, or that this occurs outside RTS generating hours. 


\section{Conclusions and Key Considerations}

The value of RTS generation ranges widely depending on local power system contexts and the value streams included in the analysis. This analysis used a combination of publicly available information, consultation with stakeholders, and a UCED model of the Indian power system to determine what the value of exports from RTS would be worth to the power system and society for each hour of a given year. The analysis focused on the states of Gujarat and Jharkhand and examined two cases, one with current levels of VRE and one with levels of VRE consistent with government targets. The following section discusses conclusions drawn from the analysis, policy implications of the results, and options available to address concerns surrounding the financial implications of RTS generation.

\subsection{Conclusions}

The analysis finds a lower VOS in the state of Jharkhand than in Gujarat, resulting chiefly from the differences in avoided energy cost and the generation capacity value. In Jharkhand, electricity generation costs are lower and the aggregate load profile is relatively flat with peaks occurring later in the day. For Gujarat, solar can provide additional benefits due to higher electricity generation costs during times of solar generation.

When summed together, the Environmental and Health VOS components are the largest portion of the VOS in both Gujarat and Jharkhand. If one considers the Environmental and Health value from RTS, for the MNRE Goals case (achieving the $175 \mathrm{GW}$ MNRE goals for renewable energy deployment), the analysis finds a total value of 9.0-10.8 rupees per $\mathrm{kWh}$ in Gujarat and 7.5-9.3 rupees per $\mathrm{kWh}$ for Jharkhand. When the Environmental and Health value is excluded from the calculations, the analysis finds a total value of approximately 2.3 and 3.8 rupees per kWh for Jharkhand and Gujarat, respectively, for the higher solar cases. Table 7 shows a comparison of the total values for the two states and two scenarios both with and without the Environmental and Health value.

Table 7. Comparison of VOS Values for Gujarat and Jharkhand for Base Case and MNRE Goals Scenarios With and Without the Environmental and Health Value (rupees per kWh)

\begin{tabular}{|l|c|c|c|c|}
\hline & \multicolumn{2}{|c|}{ Gujarat } & \multicolumn{2}{c|}{ Jharkhand } \\
\hline & Base Case & MNRE Goals & Base Case & MNRE Goals \\
\hline $\begin{array}{l}\text { With } \\
\text { Environmental } \\
\text { and Health }\end{array}$ & $10.0-11.8$ & $9.0-10.8$ & $7.6-9.3$ & $7.5-9.3$ \\
\hline $\begin{array}{l}\text { Without } \\
\text { Environmental } \\
\text { and Health }\end{array}$ & 4.8 & 3.8 & 2.3 & 2.3 \\
\hline
\end{tabular}

With the Environmental and Health benefit included, the energy charges from the retail tariffs and the sell rate (under Gujarat's net metering scheme) are lower than the overall VOS value for both states, indicating that RTS provides more benefits than costs from a societal point of view. As environmental and health benefits are not currently monetized - these are avoided externalities — utilities do not see any financial benefits from these values and would likely choose not to consider them when comparing the financial value of RTS to its costs (or reduced revenues).

In Gujarat, when environmental and health benefits are not considered in the VOS, the net financial impact of RTS depends on the tariffs of those customer installing RTS. The average power purchase cost for all DISCOMs in Gujarat is 4.3 rupees per $\mathrm{kWh}$, which is just below the Base Case VOS (4.8 rupees 
per kWh). By adding RTS, some customers are able to displace tariffs that are higher than the Base Case VOS. While this is advantageous to the customer, it would lead to a net revenue loss for those DISCOMs. For example, larger residential customers in Gujarat consuming more than $250 \mathrm{kWh}$ per month have a marginal tariff of 5.2 rupees per $\mathrm{kWh}$, which is higher than the Base Case VOS of 4.8 rupees per $\mathrm{kWh}$. While this is a benefit to the large residential customer who could pay less for RTS, this indicates a net revenue loss of 0.4 rupees per $\mathrm{kWh}$ for generation displacing monthly load above $250 \mathrm{kWh}$. Residential customers with smaller loads have lower energy charges due to the increasing block pricing structure of residential tariffs. For customers with loads less than $250 \mathrm{kWh}$ per month, the value of RTS in the base case is greater than the energy charges, which implies a net financial benefit to the utility. The overall financial impact of RTS for distribution utilities in Gujarat will hence depend on the customer mix installing RTS systems in the Base Case. This is also the case for the MNRE Goals scenario. With higher solar deployment levels, only customers in the lowest-priced tiers would lead to net benefits from RTS.

Given the lower VOS in Jharkhand, RTS leads to a net financial cost to utilities in all cases. Energy charges - a proxy for RTS compensation rates given net metering policies - are lower than the value of RTS without environmental and health considerations, regardless of customer class. The overall financial impact for Jharkhand distribution utilities will depend on the underlying tariffs of the RTS customers. Given the net metering regulations, customers who offset higher rate levels (e.g., urban customers) lead to higher DISCOM revenue losses, which would in turn lead to higher net revenue costs.

Aside from whether Environmental and Health values are included in the VOS, and in Gujarat, where customers adopt RTS, there are other key considerations. In both states, cost-shifting between RTSadopting and RTS-nonadopting customers can lead to a net cost of RTS generation and concerns of utility revenue sufficiency and resulting tariff increases. However, revenue sufficiency and cost-shifting concerns should be put into perspective before significant changes to the RTS program are considered. At relatively small differences between the VOS value and the retail tariff or sell rate, and/or at relatively low levels of RTS deployment, the net cost of the RTS program to the DISCOM are likely to be less significant than other factors that influence utility revenues such as natural gas prices, fluctuations in demand patterns, and power sector CAPEX (Barbose 2017; Tongsopit et al. 2017; Tongsopit et al. 2019; Darghouth et al. 2020). Furthermore, due to limited availability of data, this analysis excluded several RTS-related benefits including deferring investments in distribution infrastructure investments, which may increase the VOS in each state. Understanding the potential net cost or net benefit of an RTS program, and understanding this cost or benefit relative to other factors influencing utility revenues, can inform compensation mechanism design to ensure RTS programs do not become a burden on DISCOMs and ratepayers. Policymakers and regulators can use the results of this analysis to assist in decisionmaking on whether changes to compensation mechanisms should be considered, based on levels of RTS deployments, compensation rates for RTS exports, and lost revenues from RTS self-consumption.

\subsection{Implications for Decision Makers}

VOS analyses can provide important insights to policymakers, regulators, and other power system stakeholders on how RTS impacts power system operation and DISCOMs. Additional studies such as utility revenue impact or tariff impact analyses can further contribute to understanding the net impact of RTS adoption on power systems and retail tariffs. These studies can inform decisions around revising compensation mechanisms, providing an estimate for the magnitude of net impacts from RTS adoption and how those impacts might change over time with changes to the power system, retail tariff structures, RTS compensation schemes or RTS adoption. For those areas in this analysis where data was unavailable, additional or more detailed data collection could inform more accurate results.

The findings indicate that the VOS is lower than average volumetric retail energy tariffs when externalities such as environmental and health benefits are not considered. This suggests that current net 
metering regimes could potentially lead to an increase in retail tariffs during the next rate case or true-up. The retail tariff effects resulting from the difference between the VOS and the retail rate may be very small or negligible for low adoption levels, as is currently the case in Jharkhand. The tariff impacts can sometimes be lower than exogenous factors that impact retail tariffs, such as weather or fluctuations in fossil fuel prices (see for example, Barbose 2017). The magnitude of the increase in the tariff would depend on the magnitude of the difference between the VOS (not counting any externalities) and reduced utility revenue resulting from net metering policies, which depends on some of the values calculated in this analysis, as well as total RTS generation.

Decision makers often have to balance a variety of regulatory objectives that compete in many cases. In this case, they may include achieving RTS deployment targets, keeping tariffs low and equitable, and protecting the health of their citizens. With very low tariff impacts, regulators may decide that the benefits of achieving solar targets outweigh any costs related to tariff levels, particularly if vulnerable customer segments are protected from any increases in tariffs. This study's results indicate that the aggregate societal cost of any increases in tariffs would be outweighed by the environmental and health benefits, which can be taken into account when considering policy changes (See the Policy Options to Equitably Distribute Environmental and Health Benefits of RTS textbox).

These health and environmental benefits are particularly important for India, which ranks as having some of the worst air pollution (both indoor and ambient) in the world (World Health Organization 2019). In all of India, air pollution has been associated with a death rate per 100,000 residents of 89.9 , this figure drops to 69.0 and 84.9 for Jharkhand and Gujarat, respectively (Balakrishnan et al. 2019). A significant portion of air pollution can be attributed to the power sector. Baseline projections of emission sources by sector in India for 2010 indicated that approximately $53 \%$ of $\mathrm{SO}_{2}, 30 \%$ of $\mathrm{NO}_{\mathrm{x}}$, and $4 \%$ of $\mathrm{PM}_{2.5}$ total emissions could be attributed to thermal power generation (Purohit et al. 2010).

\section{Policy Options to Equitably Distribute Environmental and Health Benefits of RTS}

There are a number of policy options for decision makers to monetize the health and environmental benefits from RTS (e.g., creating markets for carbon or emissions in which generators would participate). These would allow a better alignment between the VOS to utilities and to society. Adopting these policies may further bolster and accelerate states' adoption and deployment of RTS in alignment with the government's goals for RTS. However, such measures would also have additional implications that would need to be considered, including higher average tariff levels or utility costs resulting from the additional compliance costs, for example. Though these may lead to better outcomes from a societal point of view, these benefits may not be evenly distributed across various customer groups. Some customers may be disproportionally impacted by even small increases in tariff levels, for example, although these customers may also currently be disproportionately impacted by poor air quality. Policies that directly target equity issues, such as subsidies for low- and middle-income customers, can help ensure any societal benefits are accrued more equitably.

Many of the value streams available for RTS are also achievable through utility-scale systems. Unlike utility-scale systems, however, RTS can provide additional values such as distribution system upgrade deferrals and customer energy resilience. RTS also suffers fewer losses relative to utility-scale systems when providing values such as energy and capacity, as it serves demand closer to the source of load. These additional value streams and reduced losses must be balanced against lower overall levelized costs for utility-scale systems and reduced complexity when coordinating utility-scale systems versus aggregating many distributed systems. VOS studies can help provide decision makers with quantitative results to compare the relative costs and benefits of utility-scale and RTS systems, which in turn can 
inform the development of policies to target RTS deployment in areas where it can provide unique value to the grid.

While the benefits of reduced losses were included in this study, due to data and methodological constraints the benefit of RTS to the distribution system was excluded. Furthermore, although the value of RTS generation will likely fluctuate widely across a given state, this study only looked at the average value in each state, masking exploitable high value locations. Future research into additional benefits and costs not covered here, as well as additional granularity in the analysis, could better inform discussion on RTS compensation as well as lead to novel policies that target deployment in high-value regions of the power system, where more traditional investments like utility-scale generation may not be appropriate or competitive (e.g., in a congested city network). Such a targeted approach to RTS deployment could improve utility revenue recovery and alleviate concerns of cost shifting.

\subsection{Policy Options to Address Concerns Related to the Financial Impacts of RTS}

Higher levels of RTS adoption combined with compensation through net metering policies and timeinvariant volumetric energy tariffs could lead to higher tariff impacts resulting from insufficient utility revenue recovery. Given its higher rooftop adoption levels, tariff impacts are likely to be higher in Gujarat than in Jharkhand in the short term. Barbose et al. (2016) provides an overview of the many options regulators have to address the financial impacts of RTS on utilities. These include making changes either to net metering policies or to tariff structures, with the objective of aligning solar compensation with the VOS for utilities and resulting in reduced compensation to RTS customers. Any reduction in RTS compensation would likely lead to reductions in deployment, so regulators need to consider deployment goals before making any significant changes to retail tariff structures or policies. Using the VOS directly to compensate all RTS generation at the calculated VOS (i.e., a VOS tariff) would minimize financial impacts on utilities or nonsolar adopters. This would require the regular updating of the VOS analysis, as the power system characteristics change over time; however, many jurisdictions have instead chosen to consider alternatives to net metering policies (such as net billing where any electricity injected into the grid is compensated at a tariff lower than the customer's retail tariff for electricity consumption) or changes to retail tariff design (i.e., having all solar adopters be on a time-varying tariff or imposing larger monthly customer charges while reducing volumetric energy charges).

Another strategy to minimize financial impacts on utilities or ratepayers would be to identify areas where RTS provides higher value to the system and incentivize deployment in higher value areas, resulting in a better alignment between RTS compensation and the value of RTS. This would require more geospatially granular analyses that seek to analyze the VOS at a substate level. Finally, to address the equity implications of increases in retail tariffs (because those who benefit from the tariff increases are solar system owners who are homeowners with cash or access to credit), regulators could consider policies to allow lower income renters or those living in multifamily housing to also benefit from solar through shared solar (or community solar) approaches, increased access to finance, or alternative business models (such as solar leasing or power purchase agreements). This would address some of the cost-shifting concerns while also enabling a more equitable deployment of RTS. 


\section{References}

Abas, N., A. Kalair, N. Khan, and A. R. Kalair. "Review of GHG Emissions in Pakistan Compared to SAARC Countries." Renewable and Sustainable Energy Reviews 80 (December 2017): 9901016. https://doi.org/10.1016/j.rser.2017.04.022.

Balakrishnan, Kalpana, Sagnik Dey, Tarun Gupta, R. S. Dhaliwal, Michael Brauer, Aaron J. Cohen, Jeffrey D. Stanaway, et al. "The Impact of Air Pollution on Deaths, Disease Burden, and Life Expectancy across the States of India: The Global Burden of Disease Study 2017.” The Lancet Planetary Health 3, no. 1 (2017): e26-39. https://doi.org/10.1016/S2542-5196(18)30261-4.

Barbose, Galen. 2017. Putting the Potential Rate Impacts of Distributed Solar into Context. Berkeley, CA: Lawrence Berkeley National Laboratory. LBNL-1007060. https://emp.lbl.gov/publications/putting-potential-rate-impacts.

Barbose, Galen, John Miller, Ben Sigrin, Emerson Reiter, Karlynn Cory, Joyce McLaren, Joachim Seel, Andrew Mills, Naïm Darghouth, and Andrew Satchwell. 2016. On the Path to SunShot: Utility Regulatory and Business Model Reforms for Addressing the Financial Impacts of Distributed Solar on Utilities. Golden, CO: National Renewable Energy Laboratory (NREL). NREL/TP6A20-65670. http://www.nrel.gov/docs/fy16osti/65670.pdf.

Bridge to India. 2020. “India Solar Rooftop Map.” June 2020 Solar Map.

https://bridgetoindia.com/report/india-solar-rooftop-map-june-2020/.

CAISO (California Independent System Operator). 2016. Fast Facts: What the Duck Curve Tells Us About Managing a Green Grid. Folsom, CA: California Independent System Operator. CommPR/2016. https://www.caiso.com/Documents/FlexibleResourcesHelpRenewables_FastFacts.pdf.

__ 2020. "Docket No. ER20-___-000; Tariff Amendment to Implement Demand Response Enhancements: Request for Waiver of Notice Period." California Independent System Operator. July 16, 2020. http://www.caiso.com/Documents/Jul162020 EnergyStorage_DistributeEnergyResource-ESDER-3B-ER20-2443.pdf.

CEA. 2018a. National Electricity Plan - Volume I - Generation. New Delhi, India: Central Electricity Authority. http://www.cea.nic.in/reports/committee/nep/nep jan_2018.pdf.

- 2018b. Annual Report 2017-18. New Delhi, India: Central Electricity Authority. http://www.cea.nic.in/reports/annual/annualreports/annual_report-2018.pdf.

Darghouth, Naïm R, James McCall, David Keyser, and Alexandra Aznar. 2020. Distributed Photovoltaic Economic Impact Analysis in Indonesia. Golden, CO: NREL. NREL/TP-7A40-75281. https://www.nrel.gov/docs/fy20osti/75281.pdf.

Denholm, Paul, Robert Margolis, Bryan Palmintier, Clayton Barrows, Eduardo Ibanez, Lori Bird, and Jarett Zuboy. Methods for Analyzing the Benefits and Costs of Distributed Photovoltaic Generation to the U.S. Electric Utility System. Golden, CO: NREL. NREL/TP-6A20-62447. https:/www.nrel.gov/docs/fy14osti/62447.pdf.

Energy Exemplar. 2014. “Generator: SRMC.” In PLEXOS Wiki Concise Modeling Guide. 
—. 2020. "PLEXOS Integrated Energy Model (version 7.300r04)." Energy Exemplar. https://energyexemplar.com/solutions/plexos/\#. Accessed 1 May 2020.

Government of Jharkhand. 2018. "Jharkhand State Solar Rooftop Policy 2018. Resolution No.-3134." https://www.jreda.com/upload_files/kvit131.pdf.

Gujarat Electricity Regulatory Commission. 2016. "Regulations for Net Metering Rooftop Solar PV Grid Interactive Systems.” Regulation. Gandhinagar, Gujarat: GERC. https://www.gercin.org/wpcontent/uploads/2019/08/Draft-Regulations-for-Net-Metering-Rooftop-Solar-PV-GridInteractive-Systems.pdf.

. 2019. "Truing Up for FY 2017-18, Mid-Term Review of ARR for FY 2019-20 to 2020-21 and Determination of Tariff for FY 2019-20 for Uttar Gujarat Vij Company Limited (UGVCL)." Tariff Order Case No. 1759 of 2018. Gandhinagar: GERC.

2020. "Net Metering Rooftop Solar PV Grid Interactive Systems (Second Amendment) Regulations." Notification 2. Gandhinagar, Gujarat: GERC. https://www.gercin.org/wpcontent/uploads/2020/01/GUJARAT-ELECTRICITY-REGULATORY-COMMISSION-NETMETERING-ROOFTOP-SOLAR-PV-GRID-INTERACTIVE-SYSTEMS-SECONDAMENDMENT-REGULATIONS-2020.pdf.

Gujarat Pollution Control Board. 2019. "Pilot Emissions Trading Scheme for Select Industries in Surat Gujarat.” Gandhinagar: GPCB. https://gpcb.gujarat.gov.in/uploads/GPCB ETS CIRCULAR 19112019.pdf.

Holm, Alison, Jeffrey J. Cook, Alexandra Aznar, Jason Coughlin, and Benjamin Mow. 2019. Distributed Solar Photovoltaic Cost-Benefit Framework Study: Considerations and Resources for Oklahoma. Golden, CO: NREL. NREL/TP-7A40-72166. https://www.nrel.gov/docs/fy19osti/72166.pdf.

Horowitz, Kelsey A. W., Bryan Palmintier, Barry Mather, and Paul Denholm. "Distribution System Costs Associated with the Deployment of Photovoltaic Systems." Renewable and Sustainable Energy Reviews 90 (July 2018): 420-33. https://doi.org/10.1016/j.rser.2018.03.080.

Indian Energy Exchange. 2020a. "Day-Ahead Market Area Prices.” Data Portal. Market Data. Last modified November 18, 2020. https://www.iexindia.com/marketdata/areaprice.aspx.

—. 2020b. "Bid Areas." Day-Ahead Market. Last modified November 18, 2020. https://www.iexindia.com/bidareas.aspx?id=qZpXzaO5CaM\%3d\&mid=IT8b\%2bZM5cBA\%3d.

Josey, Ann, Shantanu Dixit, Ashwini Chitnis, and Ashwin Gambhir. 2018. Electricity Distribution Companies in India: Preparing for an Uncertain Future. Pune, India: Prayas Energy Group. http://www.prayaspune.org/peg/publications/item/377.

Madaeni, Seyed Hossein, Ramteen Sioshansi, and Paul Denholm. 2012. Comparison of Capacity Value Methods for Photovoltaics in the Western United States. Golden, CO: NREL. NREL/TP-6A2054704. https://www.nrel.gov/docs/fy12osti/54704.pdf.

Mittal, Moti L, Chhemendra Sharma, and Richa Singh. 2012. "Estimates of Emissions from Coal Fired Thermal Power Plants in India.” In International Emission Inventory Conference. Tampa, FL: EPA. https://www3.epa.gov/ttn/chief/conference/ei20/session5/mmittal.pdf. 
MNRE and GOI. 2015. State Wise and Year Wise Targets for Installation of 40,000 MWp Grid Connected Solar Rooftop Systems. Vol. D.O. No. 03/13/2015-16/GCRT. http://mnre.gov.in/filemanager/UserFiles/State-wise-and-year-wise-target-for-installation-of-40000MWp-GCRTsystems.pdf.

MOEFCC (Ministry of Environment, Forest, and Climate Change). "Revised Standards for Coal-Based Thermal Power Plants." New Delhi: Ministry of Environment, Forest and Climate Change. The Gazette of India. December 8, 2015. http://www.indiaenvironmentportal.org.in/files/file/Moef\%20notification\%20-020gazette.pdf.

NITI (National Institution for Transforming India). 2015. Report of the Expert Group on 175 GW by 2022. New Delhi: NITI. https://niti.gov.in/writereaddata/files/175-GW-Renewable-Energy.pdf.

NISE (National Institute of Solar Energy). 2014. "Statewise Estimated Solar Power Potential in the Country." Gurugram, Haryana: National Institute of Solar Energy. http://www.indiaenvironmentportal.org.in/files/file/Statewise-Solar-Potential-NISE 0.pdf.

North Carolina Clean Energy Technology Center. 2020. The 50 States of Solar: 2019 Policy Review and Q4 2019 Quarterly Report. 50 States of Solar. Raleigh, NC: North Carolina Clean Energy Technology Center. https://nccleantech.ncsu.edu/wp-content/uploads/2020/01/Q4-19-Solar-ExecSummary-Final.pdf.

NREL and USAID. "RED-E India.” Data Portal. RE Data Explorer - India. 2020. https://maps.nrel.gov/rede-india. Accessed 1 August 2020.

NYPSC (State of New York Public Service Commission). 2019. Order Regarding Value Stack Compensation. In the Matter of the Value of Distributed Energy Resources. Case 15-E-0751. https://www.nyserda.ny.gov/-/media/NYSun/files/Updated-Value-Stack-Order-2019-04-18.pdf.

- 2020. Order Establishing Net Metering Successor Tariff. In the Matter of the Value of Distributed Energy Resources. Case 15-E-0751. http://documents.dps.ny.gov/public/Common/ViewDoc.aspx?DocRefId=\{E5A4CFD8-BD264287-B3F1-C1A72A3540BA\}.

Palchak, D., J. Cochran, A. Ehlen, B. McBennett, M. Milligan, I. Chernyakhovskiy, R. Deshmukh, N. Abhyankar, S.K. Soonee, S.R. Narasimhan, M. Joshi, and P. Sreedharan. 2017a. Greening the Grid: Pathways to Integrate 175 Gigawatts of Renewable Energy into India's Electric Grid, Vol. I-National Study. Golden, CO: NREL. NREL/TP-6A20-68530. https://www.nrel.gov/docs/fy17osti/68530.pdf.

- 2017b. Greening the Grid: Pathways to Integrate 175 Gigawatts of Renewable Energy into India's Electric Grid, Vol. II - Regional Study. Golden, CO: NREL. NREL/TP-6A20-68744. https://www.nrel.gov/docs/fy18osti/68744.pdf.

Power Grid Corporation of India. 2012. “Transmission Plan for Envisaged Renewable Capacity.” Vol. I. PGCI. https://www.powergridindia.com/sites/default/files/Our Business/Smart Grid/Green Energy Co rridor_Report/Vol_1.pdf. 
Purohit, P., M. Amann, R. Mathur, I. Gupta, S. Marwah, V. Verma, I. Bertok, et al. 2010. GAINS ASIA: Scenarios for Cost-Effective Control of Air Pollution and Greenhouse Gases in India. Laxenburg, Austria: IIASA. http://pure.iiasa.ac.at/id/eprint/9379/.

Shakti Sustainable Energy Foundation and ICF International. 2015. Thermal Power Plants in India: Technical Opportunities for Improving Efficiency and Reducing Emissions. Fairfax, VA: ICF International. http://www.indiaenvironmentportal.org.in/files/file/Whitepaper-Thermal-PowerFINAL.pdf.

Steward, D., and E. Doris. 2014. The Effect of State Policy Suites on the Development of Solar Markets. Golden, CO: NREL. NREL/TP-7A40-62506. https://www.nrel.gov/docs/fy15osti/62506.pdf.

Tongsopit, Sopitsuda, Owen Zinaman, and Naïm Darghouth. 2017. Understanding the Impact of Distributed Photovoltaic Adoption on Utility Revenues and Retail Electricity Tariffs in Thailand. Washington, D.C.: USAID. http://eta-publications.lbl.gov/sites/default/files/dpvrevenueimpactreport-20171127-final.pdf.

Tongsopit, Sopitsuda, Supawan Saelim, Thanawat Keereepart, Naïm R Darghouth, Alexandra Aznar, Eric O’Shaughnessy, and Surachai Chaitusaney. 2019. Distributed Photovoltaic Economic and Technical Impact Analysis in the Philippines. Washington, D.C.: USAID. http://usaidcleanpowerasia.aseanenergy.org/resource/distributed-photovoltaic-economic-andtechnical-impact-analysis-in-the-philippines/.

World Health Organization. 2019. "Global Ambient Air Quality Database (Version 14, Update 2018)." Data Portal. Air Pollution. 2019. https://www.who.int/airpollution/data/cities/en/. Accessed 1 October 2020.

Zinaman, Owen R, Alexandra Aznar, Carl Linvill, Naim Darghouth, Emanuele Bianco, and Timon Dubbeling. 2017. Grid-Connected Distributed Generation: Compensation Mechanism Basics. Golden, CO: NREL. NREL/BR-6A20-68469. https://www.nrel.gov/docs/fy18osti/68469.pdf.

Zinaman, Owen, Thomas Bowen, and Alexandra Aznar. 2020. An Overview of Behind-the-Meter SolarPlus-Storage Program Design: With Considerations for India. Golden, CO: NREL. NREL/TP7A40-74131. https://doi.org/10.2172/1665766. 


\section{A. Detailed Methodology}

This analysis calculated the VOS using two distinct methodologies:

- A VOS Full that relied on a unit commitment and economic dispatch model of the Indian power system (referred to throughout the report as a UCED model). ${ }^{14}$

- A VOS Lite that used publicly available data on historical power system operation in the state and an Excel-based model.

The approach used to calculate the VOS in each methodology was strongly influenced by the availability of data, as well as by expectations of how the results could ultimately be used. The former VOS Full methodology allowed for a highly granular approximation of the VOS in each state for future years under various power system assumptions. This approach can help policymakers understand how the VOS may change over time or under different power system operating characteristics. This section will provide some background information regarding the UCED model used in the VOS Full analysis, as well as cover the approach taken to calculate each value considered in the VOS Full results. Limitations of the VOS Full analysis are considered in Section A.9. The methodology and results for the latter VOS Lite analysis are discussed in more detail in Appendix B.

\section{A.1 Greening the Grid Pathways UCED Model}

The value of additional energy and capacity from distributed energy resources is a measure of how injections from those resources can help offset costs associated with investing in and operating the power system, and, as such, depend heavily on various power system characteristics such as the makeup and operation of the generation fleet, transmission capacity, and power system demand, among many others. ${ }^{15}$ One way to capture these various parameters is through a UCED model, which simulates how a power system would dispatch and deliver power to meet load given assumptions on that power system. A UCED model takes information on a given power system, such as transmission capacity, load, VRE availability, and conventional generating fleet characteristics and simulates how the power system would operate to meet demand at the lowest cost subject to security constraints. The model outputs important metrics for a wide variety of analyses and efforts, including VOS studies, such as system emissions, system costs, generator dispatch schedules and power flows. Figure A- 1 provides an overview of the inputs for the UCED model, the results output, and how those results might be used.

\footnotetext{
14 The UCED model used in this analysis was based on Energy Exemplar's PLEXOS Integrated Energy Model software (Energy Exemplar 2016).

15 "Injections from DERs" here can mean RTS that is either consumed on-site by the customer or exported from the customer's system to the grid. For many of the benefits and costs explored here, it ultimately does not matter whether the injections are consumed or exported to the grid, as both instances reduce the demand that must be met with centralized conventional generation. For other benefits and costs, however, such as costs associated with strengthening the distribution system to deal with reverse power flow, whether the injections are consumed on-site or exported to the grid may be more important.
} 


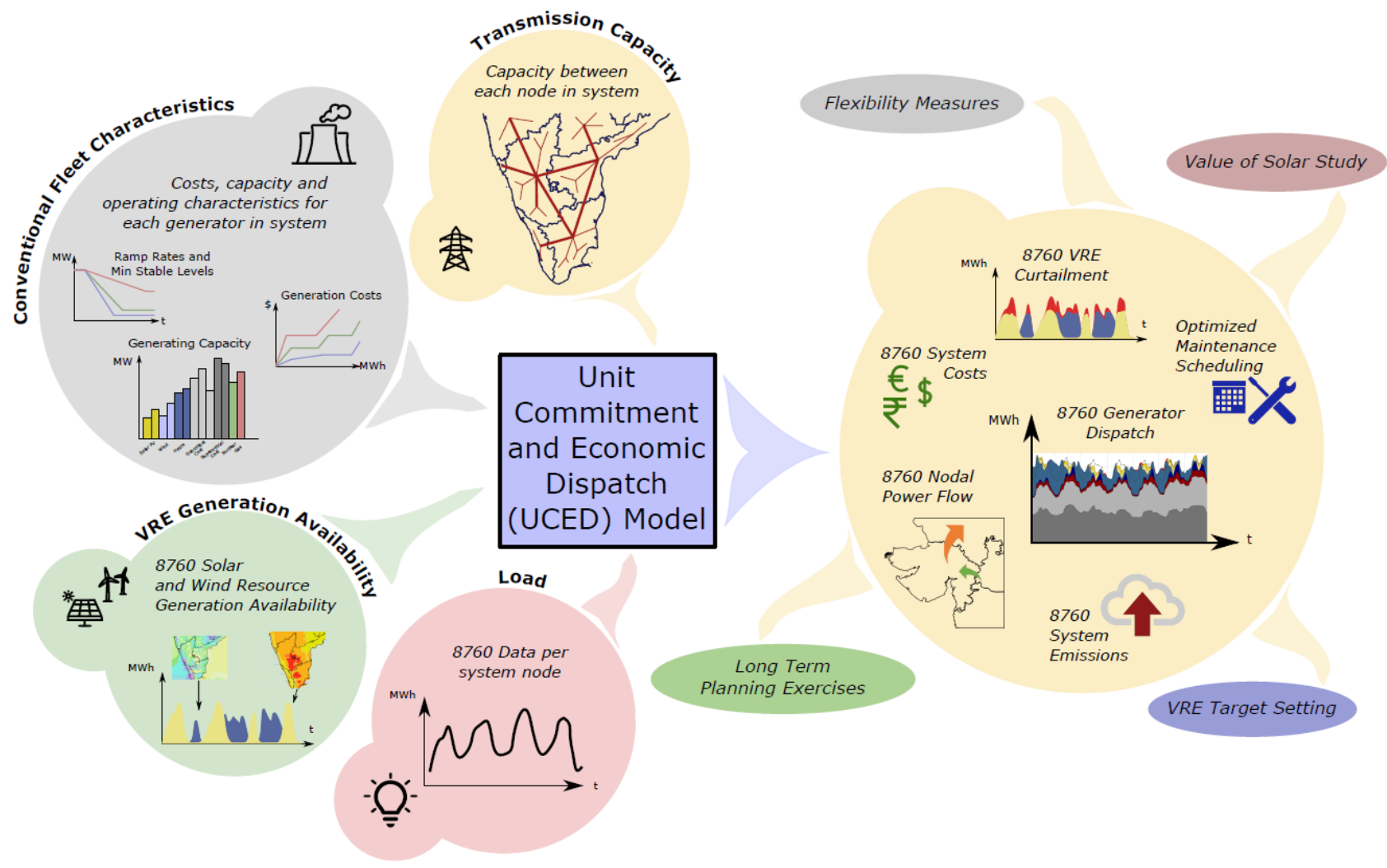

Figure A- 1. Flowchart for UCED model and results

In 2017, under the joint USAID and Government of India Greening the Grid initiative, researchers with NREL developed a UCED model of the entire Indian power system in conjunction with a multitude of stakeholders, including various DISCOMs, generation and transmission utilities, state load dispatch centers, and state and central power system operators. This model was intended to investigate how the Indian power system would respond to increasing penetrations of renewable energy to meet MNRE's ambitious 175-GW renewable energy targets (Palchak et al. 2017a, 2017b). The model considers power system operation at a 15-minute time resolution for the entire year of 2022 when the renewable energy targets are to be met. Furthermore, for a related analysis, the model was expanded into higher granularity for a subset of western and southern states to better understand the impacts of high levels of renewable energy on specific regions (Palchak et al. 2017b). ${ }^{16}$

This VOS analysis relies on the regional modeling capabilities developed in Palchak et al. (2017b) to determine hourly costs of operating the power system, as well as identify parameters such as net load critical to evaluating VOS throughout the modeled year. Two scenarios were developed using the UCED model developed in Palchak et al. (2017b):

- A Base Case scenario consisting of capacities of wind and solar targeted under the Green Energy Corridors and National Solar Mission initiatives and using the National Electricity Plan to determine the conventional generating fleet capacity in 2022.

\footnotetext{
${ }^{16}$ The study, while incorporating the entirety of India, focused on the Southern and Western regions, with specific detail afforded to the states of Andhra Pradesh, Gujarat, Karnataka, Maharashtra, Rajasthan, and Tamil Nadu.
} 
- An MNRE Goals scenario, consisting of the same thermal generating capacity as in the Base Case but assuming that the Indian government's target for $175 \mathrm{GW}$ of renewable energy would be met by 2022.

The same underlying load patterns and operational characteristics (e.g., ramp rates, transmission capacity) were assumed to be the same in both scenarios. Both scenarios were run in the UCED model to capture how the power system would operate under both sets of assumed capacity. Table A- 1 shows the assumed generating capacity for each state and all of India in more detail for the Base Case and MNRE Goals scenarios in the UCED model.

Table A- 1. Generating Capacity for 2022 in UCED Model for Base Case and MNRE Goals Scenarios

\begin{tabular}{|l|c|c|c|c|c|c|}
\hline & \multicolumn{2}{|c|}{ India (MW) } & \multicolumn{2}{c|}{ Gujarat (MW) } & \multicolumn{2}{c|}{ Jharkhand (MW) } \\
\hline Technology & Base Case & MNRE Goals & Base Case & MNRE Goals & Base Case & MNRE Goals \\
\hline Coal* & 231,316 & 231,316 & 17,024 & 17,024 & 5,800 & 5,800 \\
\hline Hydro & 58,282 & 58,282 & 1,990 & 1,990 & 130 & 130 \\
\hline RTS & 7,824 & 39,388 & 635 & 3,196 & 160 & 800 \\
\hline Utility Solar & 11,755 & 59,509 & 1,266 & 8,951 & 28 & 28 \\
\hline Wind & 50,042 & 60,023 & 7,329 & 8,808 & - & - \\
\hline Other** & 33,636 & 33,636 & 7,673 & 7,673 & - & - \\
\hline
\end{tabular}

*: Coal refers to both subcritical and super-critical coal generating capacity.

**: Other refers to biomass, cogeneration, diesel, gas, nuclear and oil generating capacity.

Finally, the UCED model was used to determine the generation profile of an "average" RTS system in both states. One of the inputs used in the UCED model is annual generation profiles (in 15-minute intervals) for RTS generators throughout India. These generation profiles, in turn, were created for the Greening the Grid study in Palchak et al (2017a; 2017b) using NREL's Renewable Energy Potential model..$^{17}$ The Renewable Energy Potential model utilizes highly granular, both spatially and temporally, irradiation data and assumptions on RTS technology characteristics to determine what the output of a RTS system would be throughout India. ${ }^{18}$ To determine the average RTS generation in a given state, the normalized output of all the RTS generation profiles in each state considered in the UCED model was averaged to yield a single representative 8,760 hourly generation profile for each state. ${ }^{19}$

\section{A.2 Energy Value}

Each generator within a utility's fleet has variable costs associated with generating power from the unit. Variable generating costs primarily refer to the fuel costs associated with generating power (e.g., the cost of the coal that must be burned) but can also include variable operating and maintenance costs. These

\footnotetext{
${ }^{17}$ https://www.nrel.gov/gis/renewable-energy-potential.html.

${ }^{18}$ A detailed treatment of how solar (and wind) generation (actual and day-ahead forecasts) was created for the UCED model is beyond the scope of this paper. For more information on how the generation profiles (and forecasted profiles) for wind and solar were created, see "Appendix A. Wind and Solar Resource Data and Generation Profiles" in Palchak et al. (2017a).

19 Thus, the 8,760 capacity factor for each RTS generator in Gujarat was averaged together to yield an average 8,760 capacity factor for RTS in the state. This capacity factor was then scaled by the assumed capacity of the new RTS generator whose value was measured for the analysis.
} 
costs are directly related to the amount of energy the generating plant is producing and thus can be avoided by reducing the level of demand they must meet. Utilities will try to meet demand in their territory by dispatching their generating fleet in the most economical way possible, subject to constraints on ensuring power system reliability or limitations of transmission capacity or individual generators. Due to this security-constrained economic dispatch, or merit order dispatch, in each hour the most expensive generator dispatched to meet load is said to be "on the margin" and would be turned down first in response to reduced demand (Denholm et al. 2014). When a distributed energy resource either meets demand at the customer's site or exports energy to meet local demand, the net effect is to reduce demand utilities must meet with centralized generating resources. Thus, the energy value of DER can be equated with the variable costs of the marginal generator in each hour the DER system is producing electricity.

In the UCED model, the variable costs of generating an incremental additional unit of power are captured through the generator's SRMC. The SRMC captures the product of the price of fuel and the marginal heat rate as well as variable operating and maintenance costs, any enforced emissions costs, and any additional system charges power system operators may require from generators.

Equation 1: SRMC Equation within the UCED model:

$$
\begin{gathered}
\text { SRMC }_{i, j}=\text { Fuel Price }_{i} \times \text { Marginal Heat Rate }_{j}+\text { VOM }_{i, j}+\text { Use of System Charge }_{i} \\
+ \text { Emission Incremental Costs }_{i, j}
\end{gathered}
$$

Notes:

The subscript $\mathrm{i}$ refers to the generator in question and $\mathrm{j}$ to its output.

$\mathrm{VOM}_{\mathrm{i}, j}$ : the variable operating and maintenance costs of generator $i$ during output $j$.

Use of System charge: the additional charge that generators may be required to pay to the market operator for delivering (power to grid) rights.

Emissions costs: the costs generators may have to pay for emissions caused by the generator. Note that for the UCED model used in this analysis, the Emissions costs were considered to be 0 and analyzed separately (see Section A.6).

Source: (Energy Exemplar 2014).

The UCED model outputs the SRMC for each generator considered in the model and for each time interval considered in the model run. As the UCED model dispatches the least expensive plants needed to meet demand, subject to other reliability requirements, the marginal generator in each time interval is the most expensive generator still dispatched to meet demand in that interval. By comparing the most expensive SRMC from the set of generators still producing with the injections from a theoretical RTS PV system, it is possible to estimate the hourly energy value for RTS injections for the modeled year.

\section{A.3 Capacity Value}

If the energy value represents the ability of RTS to reduce the variable costs associated with the generating fleet the DISCOMs must address, then the generation capacity value represents the RTS installation's ability to reduce the fixed costs of the generating fleet. Most of a customer's electricity bill, and, therefore, the DISCOM's revenue recovery, is covered by a volumetric energy charge that varies with the consumption of power from the grid. However, many of the costs associated with providing a customer with power are fixed and must be recovered regardless of a customer's total consumption. Two such fixed costs are the CAPEX required to build a new generating unit and the fixed operating and maintenance (FOM) costs associated with the generating unit. These CAPEX and FOM costs must be 
paid once the unit is built, regardless of how much energy the unit actually generates. ${ }^{20}$ As a generation fleet is ultimately sized to ensure there is adequate capacity to meet the highest periods of demand or net demand in a given year, ${ }^{21}$ any injections from a rooftop system that can be used to reduce the peak demand can help reduce the overall size of the generation fleet needed, and thus reduce associated CAPEX and FOM costs. That said, generation capacity is built to satisfy anticipated demand, and RTS cannot offset the fixed costs of existing plants, only future build-outs, so it is important to understand not only how much the next generating unit will cost, but when it is planned to be built. Figure A- 2 illustrates how the addition of RTS may be able to defer investments in traditional peaking capacity by reducing the peak net demand the power system must meet, assuming that peak demand occurs during periods of RTS power production.

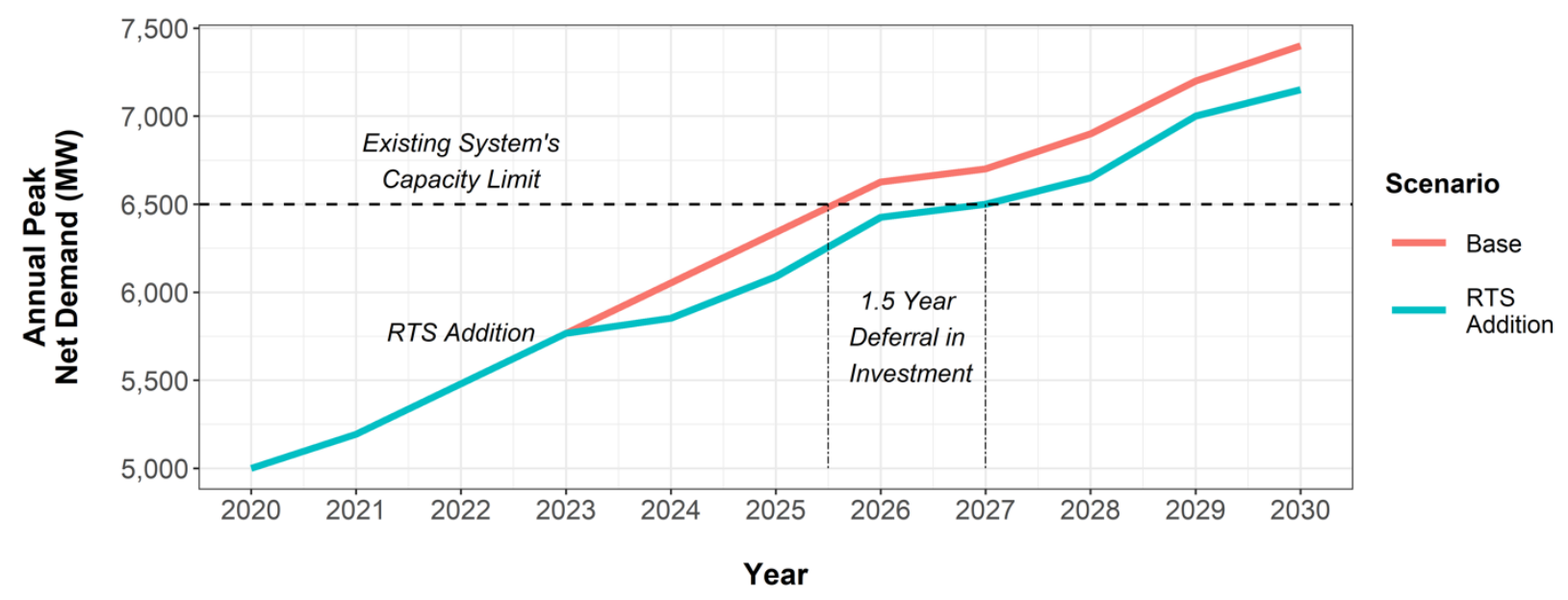

Figure A- 2. Illustrative example of RTS injections during peak demand periods deferring investments in new generating capacity

As generation is built to satisfy peak demand and peak demand occurs in a relatively limited number of hours throughout the year, it is important to account for the fact that not all RTS output will occur during periods of peak demand and thus cannot lower the corresponding need for generating capacity. One way to determine the ability of solar to address peak demand is to calculate its capacity credit (Denholm et al., 2014). The capacity credit is calculated in this analysis by measuring the average rooftop system output as a fraction of its total installed capacity, also known as its capacity factor, during a subset of hours of highest demand or net demand (Equation 2).

The VOS Full analysis uses net demand to determine the capacity credit of a theoretical RTS generator rather than total demand. Net demand better reflects the actual demand that will be used to determine

${ }^{20}$ It should be noted that how these costs must ultimately be paid depends on market structures. In some power systems, generating capacity is procured independently of energy through capacity markets (such as in PJM in the United States). Often times, utilities will not own generating capacity and will sign power purchase agreements with generator operators that determine a fixed price for energy delivery and capacity availability throughout the agreement's duration. In all cases, regardless of how the payment is structured, RTS can reduce associated generating capacity costs for utilities by reducing the amount of peak demand they must meet (e.g., the utility must either build less generating capacity, procure less capacity from a capacity market, or enter into fewer power purchase agreements).

${ }^{21}$ Net demand refers to the total demand less the generation from VRE generators (e.g., solar PV or wind) that are not dispatchable. It essentially represents the total demand that load-serving entities must meet with more conventional dispatchable resources. 
generating capacity needs and therefore the capacity value of RTS. Furthermore, using net demand better reflects the declining marginal value of RTS with increasing penetrations of RTS and utility PV on the system.

To determine the capacity value, the following was used:

- Total demand: Used to determine the net load, which is used in turn to calculate the RTS's capacity credit.

- Total variable renewable generation: Used to determine net load, which is used in turn to calculate the RTS's capacity credit.

- Theoretical RTS output: Used to calculate the RTS's capacity credit as well as to annualize the capacity value (i.e., to convert from INR/kW-year to INR/kWh value).

- Cost of next generating unit as a function of its installed capacity (i.e., INR/MW), both its CAPEX and FOM costs.

- Next year in which new generating capacity is needed: Used to determine how much costs of future generating capacity should be discounted in today's value (determined by net present value calculation).

- Assumed discount rate: Used in discounting values through net present value calculation.

- Assumed debt-equity ratios for how much of the generating plant's full costs are paid in the first year (equity) and how much are paid over time through a loan (debt), as well as the interest rate for the loan for the generating plant.

Given these values, the capacity value in any given hour can be calculated as follows:

Equation 2: Calculation of the Capacity Credit $^{22,23}$

$$
\text { Capacity Credit }_{R T S}=\frac{\sum_{i}^{n} \text { Instantaneous Output }_{R T S, i} / \text { Capacity }_{R T S, i}}{n}
$$

Where:

$\mathrm{n}$ : the number of top demand (or net demand) hours (i) considered when determining the need for capacity in planning exercise. $\mathrm{N}$ represented $3 \%$ of all hours in the year for this analysis.

Thus, Equation 2 essentially consists of taking the average capacity factor of the RTS system in question for the top $n$ hours of demand (or net demand) in a given year.

\footnotetext{
${ }^{22}$ Equation 2 represents a very simplified approximation method for determining the capacity credit of an RTS system. For a more in-depth treatment on calculating the capacity credit of solar PV systems, see Madaeni et al. (2012).

${ }^{23}$ As an example, if $n$ is 5 hours (for this analysis $n$ was set to be $3 \%$ of hours out of the year or 263 hours) and the output of a $5 \mathrm{~kW}$ RTS system during the 5 hours of highest power system net demand was $[0 \mathrm{~kW}, 3 \mathrm{~kW}, 4 \mathrm{~kW}, 0$ $\mathrm{kW}, 3 \mathrm{~kW}]$, then the capacity credit would be the average of those capacity factors $[0 \mathrm{~kW} / 5 \mathrm{~kW}, 3 \mathrm{~kW} / 5 \mathrm{~kW}, 4$ $\mathrm{kW} / 5 \mathrm{~kW}, 0 \mathrm{~kW} / 5 \mathrm{~kW}, 3 \mathrm{~kW} / 5 \mathrm{~kW}$ ] or .4 (unitless).
} 
Equation 3: Calculation of the Net Present Value for CAPEX-FOM costs and RTS Generation

$$
N P V=R_{0}+\sum_{t=1}^{n-1} \frac{R_{t}}{(1+i)^{t}}
$$

Where:

$\mathrm{R}_{0}$ : The initial year of generation for the RTS unit or the initial cash flow for the first year of the conventional generating unit: equity portion of CAPEX costs, FOM costs, and annual loan payment. Annual loan payment based on assumed duration of loan, assumed principal, and assumed loan interest rate.

$\mathrm{R}_{\mathrm{t}}$ : Generation for the RTS unit or the cash flows for the conventional generating unit (FOM costs and annual loan payment), except the initial year.

$\mathrm{n}$ : Number of years for RTS or next assumed conventional generator operation.

i: Discount rate, assumed.

Equation 4: Calculation of the Capacity Value

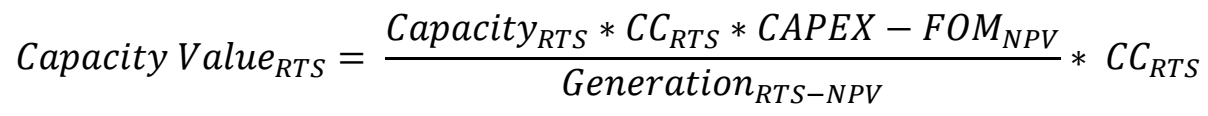

Where:

Capacity RTs: Installed capacity of the rooftop system.

$\mathrm{CC}_{\mathrm{RTS}}$ : Capacity credit of the rooftop system.

CAPEX-FOM $\mathrm{NPV}_{\mathrm{N}}$ Net present value of the capital and FOM costs associated with the next generating unit to be built.

Generation RTS-NPV: Net present value of the annual generation of the RTS system.

The sources for this data are detailed in Table A- 2 .

Note the capacity credit appears twice in Equation 4. This is because the equation must:

- Determine the fraction of the total capacity of the theoretical rooftop system which can be relied upon during periods of peak demand.

- Account for the fact that even though the capacity value is calculated as a share of annual generation, peak demand only occurs in a certain share of hours, and, therefore, the annual generation must be normalized in a sense. 


\begin{tabular}{|c|c|c|c|}
\hline Data & Use & $\begin{array}{l}\text { Source for VOS } \\
\text { Full Analysis }\end{array}$ & Value \\
\hline Total Demand & $\begin{array}{l}\text { Total demand was used together with variable } \\
\text { renewable generation to determine the top } n \text { hours } \\
\text { of net demand, which was used in calculating the } \\
\text { capacity credit of the RTS system (Equation 2). }\end{array}$ & UCED model & 8760 data \\
\hline $\begin{array}{l}\text { Variable Renewable } \\
\text { Generation }\end{array}$ & $\begin{array}{l}\text { Variable renewable generation was used together } \\
\text { with total demand to determine the top } n \text { hours of } \\
\text { net demand, which was used in calculating the } \\
\text { capacity credit of the RTS system (Equation 2). }\end{array}$ & UCED model & 8760 data \\
\hline $\begin{array}{l}\text { Instantaneous RTS } \\
\text { Output }\end{array}$ & $\begin{array}{l}\text { Used in calculating the capacity credit for the RTS } \\
\text { system (Equation 2). }\end{array}$ & UCED model & 8760 data \\
\hline $\begin{array}{l}\text { CAPEX Cost of Next } \\
\text { Generator (e.g., a } \\
\text { supercritical coal plant) }\end{array}$ & Used in calculating the capacity value (Equation 4). & $\begin{array}{l}\text { Discussion with } \\
\text { Stakeholder }\end{array}$ & $\begin{array}{l}60,000,000 \\
\text { INR/MW }\end{array}$ \\
\hline $\begin{array}{l}\text { FOM Cost of Next } \\
\text { Generator (e.g., a } \\
\text { supercritical coal plant) }\end{array}$ & Used in calculating the capacity value (Equation 4). & $\begin{array}{l}\text { Assumed to be } \\
2 \% \text { of the } \\
\text { CAPEX costs }\end{array}$ & $\begin{array}{l}1,200,000 \\
\text { INR/MW-year } \\
\text { (paid every year) }\end{array}$ \\
\hline $\begin{array}{l}\text { Year When Next } \\
\text { Generating Unit Needed }\end{array}$ & $\begin{array}{l}\text { Used to determine the net present value of the } \\
\text { CAPEX and FOM costs of the next generator and } \\
\text { the net present value of the generation from the } \\
\text { RTS system (Equation } 4 \text { ). }\end{array}$ & Assumed & 2022 \\
\hline Lifetime of RTS System & $\begin{array}{l}\text { Used to determine the net present value of the } \\
\text { CAPEX and FOM costs of the next generator and } \\
\text { the net present value of the generation from the } \\
\text { RTS system (Equation } 3 \text { ). }\end{array}$ & Assumed & 20 years \\
\hline Discount Rate & $\begin{array}{l}\text { Used to determine the net present value of the } \\
\text { CAPEX and FOM costs of the next generator and } \\
\text { the net present value of the generation from the } \\
\text { RTS system (Equation } 3 \text { ). }\end{array}$ & Assumed & $9.00 \%$ \\
\hline Debt-Equity Ratio & $\begin{array}{l}\text { Used to determine the cashflows needed to cover } \\
\text { the full cost of the next generator, which influences } \\
\text { the net present value of the CAPEX and FOM costs } \\
\text { of the next generator (Equation 3). }\end{array}$ & Assumed & $\begin{array}{l}20 \% \text { equity } \\
80 \% \text { debt }\end{array}$ \\
\hline Loan Interest Rate & $\begin{array}{l}\text { Used to determine the cashflows needed to cover } \\
\text { the full cost of the next generator, which influences } \\
\text { the net present value of the CAPEX and FOM costs } \\
\text { of the next generator (Equation } 3 \text { ). }\end{array}$ & Assumed & $10.00 \%$ \\
\hline Loan Duration & $\begin{array}{l}\text { Used to determine the cashflows needed to cover } \\
\text { the full cost of the next generator, which influences } \\
\text { the net present value of the CAPEX and FOM costs } \\
\text { of the next generator (Equation 3). }\end{array}$ & Assumed & 20 years \\
\hline
\end{tabular}




\section{A.4 Transmission Capacity Value}

Similar to generating capacity, the transmission system used to deliver energy between neighboring power systems and between generators and customers is primarily sized to be able to address the highest periods of demand for the power system. RTS can help defer the need for new transmission infrastructure by reducing the need to deliver power over the transmission by meeting that demand locally. RTS can also provide a form of transmission value by reducing the levels of congestion on the transmission system. Congestion refers to periods of time when transmission constraints on the amount of energy that can flow through certain transmission lines or equipment result in a suboptimal dispatch of the generation fleet to meet demand. RTS's ability to meet demand locally means that that demand does not need to be met through centralized generators and, subsequently, less energy must be delivered through the transmission system. This can result in lower overall energy prices by reducing congestion on these lines and allowing for a more optimal dispatch of the generating fleet or more optimal imports and exports. This value is distinct from the energy value which captures the benefit of reducing output from the marginal generator.

The VOS Full methodology attempts to capture the transmission capacity value through the latter method by attempting to measure the economic benefit of reducing congestion on existing transmission as opposed to reducing the need for new transmission capacity. To calculate this economic benefit, the analysis looked at the locational marginal price, or nodal price, at all the nodes within the power system model for the state. Each node in the power system model is associated with a particular set of transmission lines that connects it with other nodes throughout the larger power system. By measuring the difference between prices at two nodes, one can estimate the benefit of reducing transmission congestion, assuming that less congestion on a given line would allow power to flow from lower priced nodes to higher priced nodes.

\section{A.5 Avoided Transmission and Distribution Loss Value}

When utilities deliver energy from large, centralized generators such as coal, nuclear, or natural gas plants to meet customer demand, that delivery suffers from losses on both the transmission system and distribution system. These losses are caused by several physical processes, including energy being converted into heat due to the resistance in the wires and other equipment that the energy must travel through on its way from the generators to the end-use customers. Compared to satisfying demand from centralized generating resources, meeting customer demand with generators located nearby on the distribution system suffers relatively few losses. This is particularly true in the case of behind-the-meter systems satisfying onsite customer demand. To account for these reduced losses, the energy, generating capacity, transmission capacity, and environmental and health values should all be scaled up by the appropriate transmission and distribution losses. Less energy is ultimately required from distributed assets than centralized assets to meet demand, while the same amount of the RTS capacity (subject to its capacity credit) can meet more peak demand than centralized assets.

The total calculated annual energy, generating capacity, transmission capacity, and environmental and health values were all scaled up by either the combined transmission and distribution losses or just the transmission losses, as appropriate. Table A- 3 shows which losses were used to scale up which values and the actual system losses applied. The losses were determined through publicly available utility tariff orders (Gujarat Electricity Regulatory Commission 2019). As data on the average transmission and distribution losses for the Gujarat system were more readily available than for Jharkhand, the loss estimates were assumed to be the same in both states. Note that these losses only refer to technical losses (those created by physical processes in the equipment transmitting energy between the generation source and demand) and not to commercial losses (caused by theft). 
Table A- 3. Transmission and Distribution Losses Assumed for Scaling-Up Values

\begin{tabular}{|l|l|l|l|}
\hline \multicolumn{1}{|c|}{ Value } & $\begin{array}{l}\text { Average Transmission } \\
\text { Losses Assumed }\end{array}$ & $\begin{array}{l}\text { Average Distribution } \\
\text { Losses Assumed }\end{array}$ & Total Scale-Up Assumed \\
\hline Energy & N/A & $9.90 \%$ & $9.90 \%$ \\
\hline Generating Capacity & $3.90 \%$ & $9.90 \%$ & $13.80 \%$ \\
\hline Transmission Capacity & $3.90 \%$ & $9.90 \%$ & $13.80 \%$ \\
\hline Environmental and Health & N/A & $9.90 \%$ & $9.90 \%$ \\
\hline
\end{tabular}

Source: (p. 51, Gujarat Electricity Regulatory Commission 2019)

\section{A.6 Environmental and Health Value}

Many large centralized generators are sources of pollution, including $\mathrm{SO}_{2}, \mathrm{NO}_{\mathrm{X}}$, particulate matter, and $\mathrm{CO}_{2}$. These pollutants can have significant, detrimental environmental and health effects at the local, national and global level. Compared to such generators, renewable distributed energy resources are much cleaner and can reduce $\mathrm{SO}_{2}, \mathrm{NO}_{x}$, particulate matter, and $\mathrm{CO}_{2}$ emissions. Calculating the Environmental and Health Value consists of:

1. Identifying the marginal generator during the hours the solar PV system is generating.

2. Identifying the avoided emissions associated with the marginal generator identified in (1).

3. Identifying the costs avoided from reduced emission when that marginal generator is turned down in response to decreased demand.

4. Taking the product of (2) $\times(3)$ and RTS generation at the hour in question.

The Environmental and Health value is similar to the Energy value, however, the environmental and health costs associated with pollution from fossil fuel generation are not directly paid by the utilities or power system operators, and are instead borne indirectly by all of society.

The variable health and environmental costs associated with thermal generation were determined through a literature review, which yielded an INR/ton of relevant pollution value. This value was combined with an assumed average heat rate of the thermal generation fleet (in this case, coal was assumed to be the marginal generator) to yield a INR/MWh environmental and health value for avoided thermal generation. ${ }^{24}$ Table A- 4 highlights the emission rates and emission costs used to determine the environmental health value.

\footnotetext{
${ }^{24}$ Although it was assumed that a single generator (or type of generator) is on the margin during all periods of RTS injections, in reality, the generator (or type of generator) on the margin will change throughout the year due to factors such as demand or planned and unplanned outages. Thus, in some hours, a gas plant or hydropower plant may be on the margin rather than coal. Given the preponderance of coal in the power system, and due to limited data on the emissions rates of natural gas plants in India, the actual Environmental and Health value of RTS was approximated by assuming coal was always on the margin.
} 


\begin{tabular}{|l|l|l|l|l|l|l|}
\hline \multicolumn{5}{|l|}{ Table A- 4. Low and High Bounds for Emission Rates and Emission Values Assumed in } \\
Analysis \\
\hline Pollutant & $\begin{array}{l}\text { Emissions Rate for Coal } \\
\text { (kg/MWh) }\end{array}$ & \multicolumn{3}{l|}{ Emissions Value (INR/kg) } & \multicolumn{1}{l|}{$\begin{array}{l}\text { Avoided Emissions Costs } \\
\text { (environmental and health } \\
\text { value) (INR/MWh) }\end{array}$} \\
\hline & Low Bound & High Bound & Low Bound & High Bound & Low Bound & High Bound \\
\hline NOx & 4.22 & 4.38 & 426 & 497 & 1,798 & 2,177 \\
\hline SO 2 & 6.94 & 7.20 & 284 & 355 & 1,971 & 2,556 \\
\hline CO 2 & 910 & 1051 & 1.07 & 1.42 & 969 & 1,492 \\
\hline $\begin{array}{l}\text { Particulate } \\
\text { Matter }\end{array}$ & .98 & 1.29 & 5 & 100 & 5 & 129 \\
\hline $\begin{array}{l}\text { Sources for emissions rates: (Mittal et al. 2012; MOEFCC 2015; Shakti Sustainable Energy Foundation and ICF } \\
\text { International 2015) } \\
\text { Sources for emissions values: (Abas et al. 2017; Gujarat Pollution Control Board 2019) }\end{array}$ \\
\hline
\end{tabular}

\section{A.7 RTS Integration Costs}

While RTS can provide the power system and society at large many benefits, there are costs associated with integrating RTS with the broader power system. These costs are separate from lost revenues for the DISCOM due to offset sales of electricity from demand met by RTS exports. Such costs can include those associated with installing new capacitor banks or changing equipment settings for dealing with fluctuations in voltage on distribution feeders, or reconductoring lines or replacing transformers for dealing with thermal overloading on distribution equipment. ${ }^{25}$

The value for this analysis was constant as a function of RTS exports (INR/MWh) and was estimated as $25 \%$ of the average integration costs in the United States for an estimate of RTS integration costs in Jharkhand and Gujarat. ${ }^{26}$ While this analysis uses a flat INR/MWh estimate for the integration cost, actual integration costs will vary widely between RTS installations driven by RTS system characteristics and local power system conditions. DISCOMs and regulators can help drive RTS installations in locations

\footnotetext{
${ }^{25}$ For a more in-depth treatment on RTS integration costs, factors that influence such costs, and methodologies for determining such costs, see Horowitz et al. (2018).

${ }^{26}$ The average estimated integration costs for RTS in the United States is 5 USD/MWh and conversion between INR and USD was estimated to be 71 INR to 1 USD. Furthermore, integration costs are partially driven by labor costs during the interconnection process. To capture lower overall labor costs in India relative to the United States, a derating factor of $25 \%$ was assumed for overall integration costs. The final integration cost was then 5 [USD/MWh] * $71[\mathrm{INR} / \mathrm{USD}] * .25$, which equals approximately $90 \mathrm{INR} / \mathrm{MWh}$. This cost was approved by in-country partners.
} 
with low associated integration costs through appropriate interconnection processes that communicate local power system conditions to customers and developers, such as hosting capacity maps. ${ }^{27}$

\section{A.8 RTS Program Administrative Costs}

RTS program administrative costs represent the cost to the DISCOM to create and maintain a net metering, net billing, or similar compensation mechanism program. These costs can include things such as customer education and outreach or labor costs for checking interconnections of customer-sited RTS. As an RTS program consists of upfront and ongoing expenses for the DISCOM, calculating the cost to the utility in a given year requires a net present value calculation (Equation 5). For this analysis, program administrative costs were assumed to be borne prior to the year of the analysis. Better input information on when the RTS program was initiated as well as its initial costs could allow for a more comprehensive calculation of the program administrative costs. Assumptions for the administrative costs of the program are given in Table A-5.

Equation 5: Generalized Equation for Calculating the Program Administrative Costs for RTS on a Per-kwh Basis

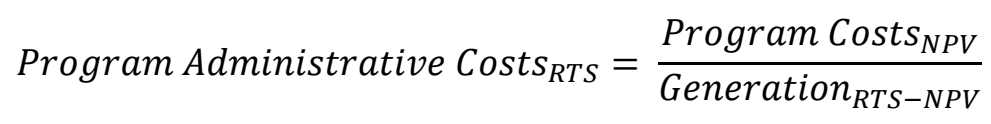

Where:

Program Costs $_{\mathrm{NPV}}$ : Net present value of the upfront initial and annual costs associated with creating and maintaining an RTS program.

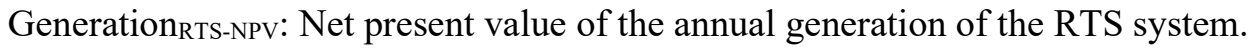

\begin{tabular}{|l|l|l|}
\hline \multicolumn{2}{|l|}{ Table A-5. Assumed Values for Calculation of Program Administrative Costs for } \\
an RTS Program
\end{tabular}

${ }^{27}$ For more information on how to incentivize deployment of RTS in areas with fewer integration costs, see Zinaman et al. (2020) and Horowitz et al. (2019). 


\section{A.9 Limitations of the VOS Full Methodology}

Although the UCED model does include more granularity and optimizes dispatch over the lifetime of the system, there are a number of limitations that should be acknowledged related to the model. First, the model was first developed in 2016 and updated in 2018, and some of the inputs used may not reflect current conditions or projections for capacity expansions (both renewable and conventional). Also, the inputs and assumptions for the Jharkhand UCED modeling were not as detailed as those for the Gujarat model: the original study in Palchak et al. (2017b) explicitly developed a granular state-level model for select states in India, including Gujarat. There is higher confidence in the Gujarat UCED model (VOS Full), which underwent more rigorous validation efforts, compared to the Jharkhand UCED results (VOS Full).

This VOS Full approach is only an estimation of how the power system operates and does not consider factors that might impede RTS's abilities to offset certain generators, such as transmission constraints, or the inability of certain plants to fully turn down their generation in response to injections of solar power. ${ }^{28}$ Given small assumed amounts of solar generation, however, it is reasonable to assume that the operation of the power system would not change considerably and that such limitations would not be breached. One additional consideration not captured in this approach is the operation of generating plants with low marginal costs but limited fuel sources, such as hydropower. The operation of these plants is primarily determined by its availability (the amount of water in the reservoir), and given its low variable costs, these plants are likely to be dispatched to meet demand whenever available.

In addition to the limitations of the UCED modeling, this analysis did not quantify other value streams that could increase the societal value of rooftop solar. For example, the analysis does not consider distribution capacity value in this analysis. If solar can reliably reduce peak load on distribution feeders, then upgrades to those distribution feeders can be avoided or at least delayed. This analysis can be complex and intense, given the data needs and the large diversity in distribution feeder types, load shapes, and topographies (e.g., rural vs. urban, residential vs. commercial, radial vs. parallel vs. ring main).

VOS analyses, regardless of the methodology, typically only provide the VOS for a snapshot of time. As the VOS depends primarily on the conditions of the power system in which it is installed, changes in the power system will yield changes in the types and magnitudes of values RTS can provide. The power system of India is undergoing significant changes, driven by growing demand and ambitious renewable energy targets, and, as such, the VOS in any Indian state is liable to also change significantly in the coming years. Thus, the results from this analysis should be used to inform near-term decisions and be taken as a general indication of how those values might change at higher penetrations of renewable energy, in particular solar. The methodology used here, however, (and in particular the methodology for the VOS Lite approach discussed in Appendix B) can be used to estimate VOS under near-future conditions to help determine the impact of growing penetrations of RTS on the power system, DISCOM revenue sufficiency, and society more broadly.

\footnotetext{
28 The UCED model which was used in this analysis did consider transmission constraints and generator flexibility for the exogenous levels of utility-scale solar PV and wind and RTS considered under the Base Case and MNRE Goals scenarios. However, for the additional marginal RTS system analyzed, the UCED model was not run and it was assumed that such relatively small levels of power injections would not impact power system operation.
} 


\section{B.VOS Lite: Results and Methodology}

In addition to the VOS Full analysis, a VOS Lite analysis was also conducted using publicly available, historical data on the operation of the power system in Jharkhand and a simplified Excel-based model. The motivations for this secondary analysis are covered in more detail in the text box at the end of Section 2. The VOS Lite analysis attempts to answer the same question as the VOS Full analysis: What is the value to the broader power system and to society at large? The VOS Lite methods differ dramatically in the data and modeling capability required; the level of detail of the results; the level of detail captured on how the power system would actually respond to exports of RTS; and the ability to forecast how the results might change under future scenarios. Broadly speaking, the VOS Lite and VOS Full methodologies represent a trade-off in the sophistication and time required versus the granularity of results and ability to test how the value might change given different assumptions about the future.

The VOS Lite methodology is based on a highly simplified assumption of how the power system would actually react to injections of RTS generation. While this is suitable for relatively minor injections of RTS, at higher levels of RTS exports the power system may begin to change its operation more substantially, which is not captured by the VOS Lite approach. Furthermore, the VOS Lite approach relies on historical data and may be inappropriate for forecasting or scenario-building, as the full scope of how the power system might evolve under different assumptions is ignored. That said, the VOS Lite approach provides a more transparent and comprehensible approach to determining the VOS. Furthermore, as it relies on publicly available data and simple modeling software (Excel), this approach can be more readily applied to other states or jurisdictions than the VOS Full approach. Despite their limitations, both the VOS Lite and the VOS Full methodologies provide actionable results, which utilities and policymakers can use to evaluate existing compensation mechanism frameworks and determine the net impact of RTS on their power system.

\section{B.1 VOS Lite Methodology}

This section details the methodology used to calculate the Energy and Generating Capacity values in the VOS Lite approach. The Transmission Capacity, Environmental and Health, and Avoided Transmission and Distribution Loss values were not calculated independently for the VOS Lite approach and in the results were assumed to be the same as in the VOS Full Base Case scenario. As the VOS Lite approach relied on historical data rather than a UCED model, scenarios were not considered.

\section{B.1.1 VOS Lite: Energy Value}

To estimate the Energy value for the VOS Lite approach, this analysis utilized publicly available data on energy exchange prices. The Indian Energy Exchange (IEX) provides 15-minute and hourly prices for several "bid areas" within the Indian exchange market for several years. Figure B- 1 shows the average IEX prices for 2019 by season over the course of a 24-hour period in the E1 bid area, to which Jharkhand belongs. ${ }^{29}$

${ }^{29}$ Day-ahead IEX market data can be found at Indian Energy Exchange (2020a), a map of the bid areas can be found at Indian Energy Exchange (2020b). Jharkhand is included in the 'E1' bid area. 


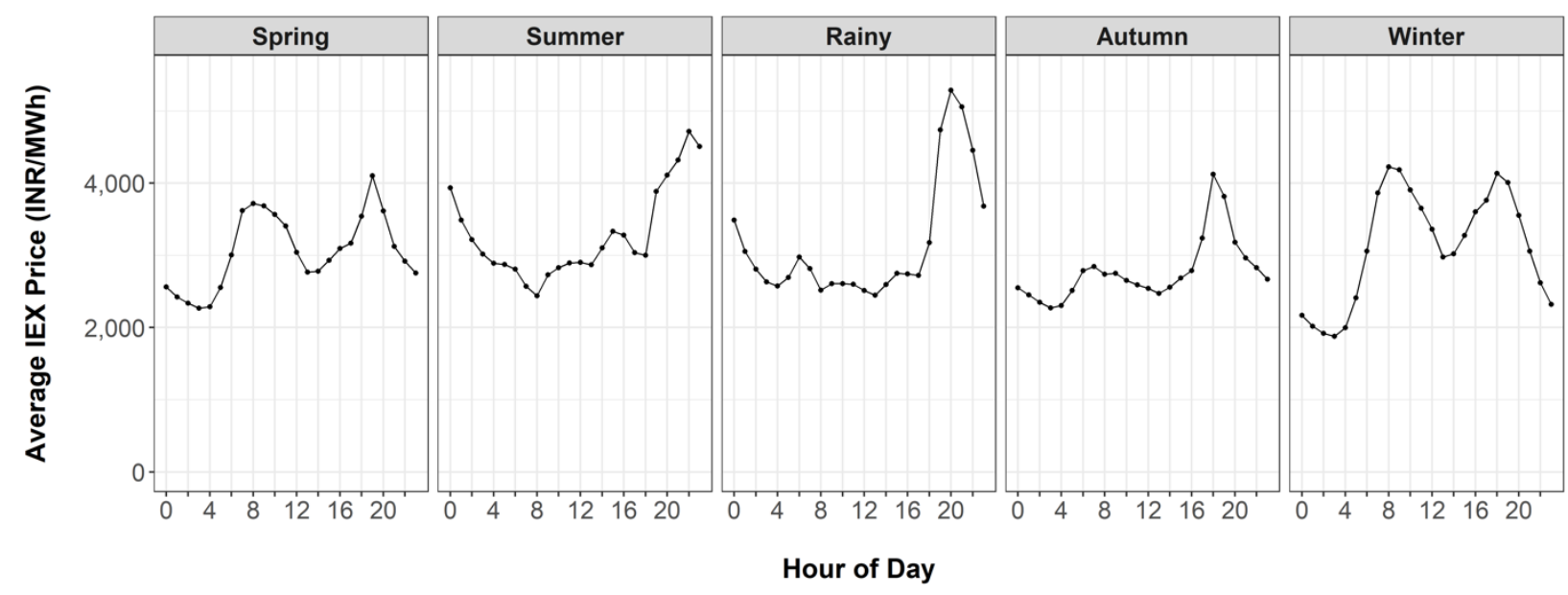

Figure B-1. Average day-ahead IEX prices for Bid Area E1 for 2019, by season and hour.

Note: for an explanation of the seasons, see the note under Figure 3.

The prices represent the cost of purchasing volumes of energy that DISCOMs may need to pay due to constraints on their own generation or generation from independent power producers operating in their area. These constraints may be due to unforeseen outages, higher-than-expected demand, transmission constraints, or limits on the ability of the generation fleet to ramp up their generation. These prices conversely also represent the revenue such DISCOMs could expect to accrue for any volumes sold to the exchange market within that period, assuming an offtaker for the energy can be found.

If injections from RTS systems can be assumed to either reduce the need to purchase from the exchange market, or to increase the energy available to sell on the exchange market, depending on whether a DISCOM has purchased enough generation to meet its demand obligations, then these energy prices represent the energy value of those RTS injections. This hourly data can then be used in conjunction with information on the theoretical output from an RTS installation to calculate the total energy value. Therefore, in this method, the Energy value was assumed to be the product of the IEX price for Bid Area E1 (INR/MWh) and the RTS system exports (MWh) in a given hour. 


\section{Alternative Energy Value Methodology: The Dispatch Stack Method}

In addition to using energy exchange data, one alternative approach to calculating the energy value of RTS generation would be to determine which generator would be on the margin in any given hour for the analysis year. Given information on the variable operating costs of generators used to meet demand in Jharkhand, granular information on the demand in the state, and assumptions on the operation of the generating fleet and its availability, it would be possible to determine the marginal generator in each hour (i.e., the most expensive generator that might be dispatched to meet demand). As RTS generation would likely help to offset demand, the most expensive generator would be turned down in response to these exports, and the energy value would therefore be equivalent to the avoided variable costs associated with that particular generator.

To show how this method might be employed, Figure B- 2 shows a dispatch stack for a given power system at three different levels of demand (Low, Mid, and High from left to right). As demand increases within the power system, more expensive generators must be turned on to meet the demand, moving to the right along the graph's $\mathrm{x}$-axis. As RTS injections would reduce the demand that must be met, the energy value of its injections can be considered to be equal to the variable costs of the marginal generator, or the Short Run Marginal Costs (represented along the y-axis).
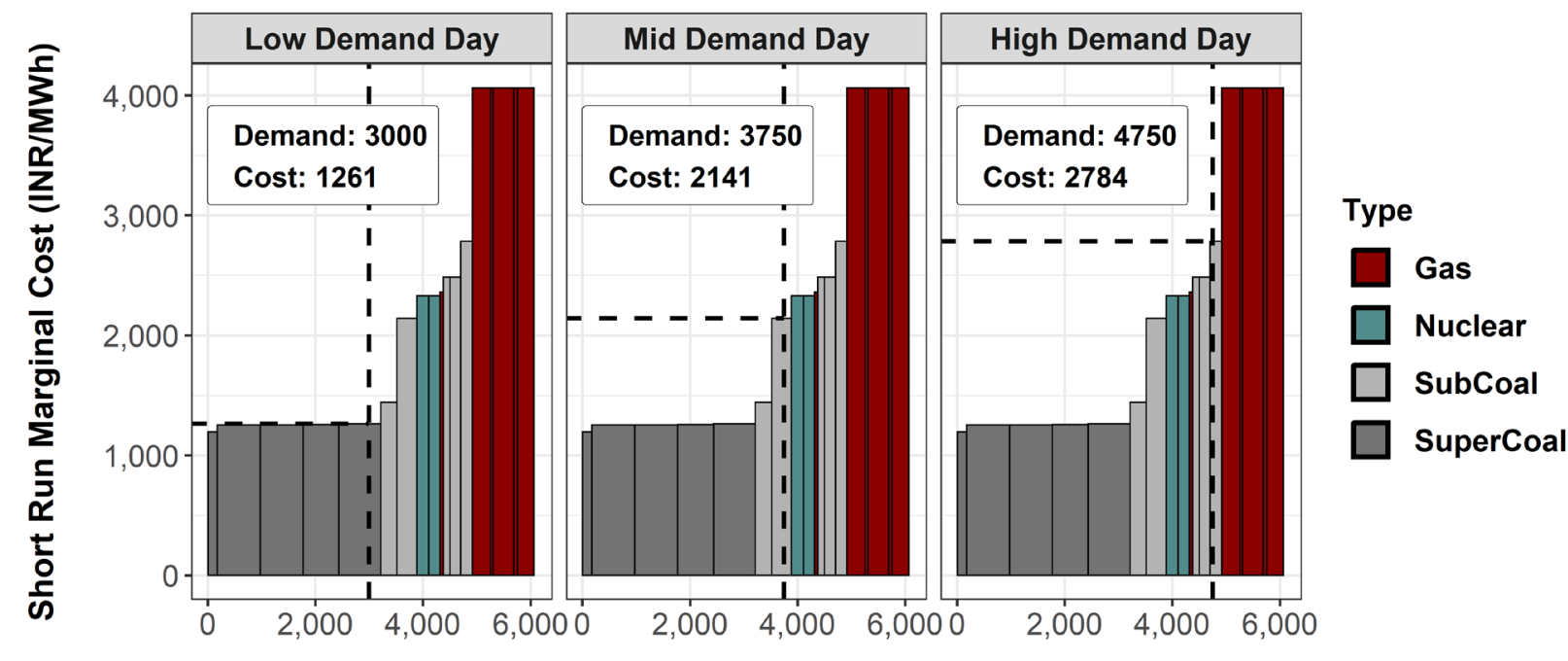

\section{Capacity (MW)}

Figure B- 2. Example of calculation of the energy value of RTS using the Dispatch Stack Method

\section{B.1.2 VOS Lite: Generating Capacity Value}

The method used to calculate the Generating Capacity value for Jharkhand in the VOS Lite approach is similar to the method used in the VOS Full approach (see Section A.3). The primary difference is that, whereas the VOS Full approach used the net peak demand (or the total demand less the VRE generation) to determine RTS's capacity credit, the VOS Lite approach used total demand. The total demand was used for the VOS Lite approach as there is not currently a significant amount of solar PV in Jharkhand and reliable granular data on VRE generation in the state could not be found. For both the VOS Full and VOS Lite approaches, Equation 4 was used to calculate the Generating Capacity value. Table B- 1 compares the sources of data for inputs into calculating the Generating Capacity value for the VOS Full and VOS Lite. 


\section{Table B- 1. Comparison of Data Sources for Inputs Into the Generating Capacity Value for VOS Full and VOS Lite Analyses}

\begin{tabular}{|l|l|l|l|}
\hline Data & Source for VOS Full & Source for VOS Lite & Value \\
\hline Total Demand & UCED model & State Load Dispatch Center* & 8760 data \\
\hline $\begin{array}{l}\text { Variable Renewable } \\
\text { Generation }\end{array}$ & UCED model & Not Used & 8760 data \\
\hline Theoretical RTS output & UCED model & UCED model & 8760 data \\
\hline $\begin{array}{l}\text { CAPEX Cost of Next } \\
\text { Generator }\end{array}$ & $\begin{array}{l}\text { Discussion with } \\
\text { Stakeholder }\end{array}$ & Discussion with Stakeholder & $60,000,000$ INR/MW \\
\hline $\begin{array}{l}\text { FOM Cost of Next } \\
\text { Generator (e.g., a } \\
\text { supercritical coal plant) }\end{array}$ & Assumed & Assumed & $\begin{array}{l}1,200,000 \text { INR/MW- } \\
\text { year (paid every year) }\end{array}$ \\
\hline $\begin{array}{l}\text { Year When Next } \\
\text { Generating Unit Needed }\end{array}$ & Assumed & Assumed & 2022 \\
\hline Discount Rate & Assumed & Assumed & $\begin{array}{l}30 \% \text { equity } \\
70 \% \text { debt }\end{array}$ \\
\hline Lifetime of RTS System & Assumed & Assumed & $11.50 \%$ \\
\hline Debt-Equity Ratio & Assumed & Assumed & 20 years \\
\hline Loan Interest Rate & Assumed & Assumed & $11.50 \%$ \\
\hline Loan Duration & Assumed & years \\
\hline Fon & & & \\
\hline
\end{tabular}

${ }^{*}$ For the VOS Lite approach, representative load patterns using actual load from a subsection of the Jharkhand power system were utilized. Since load patterns are only used to determine the alignment between peak demand and RTS generation, the less-than-complete load profiles were adequate for determining the RTS's capacity credit.

\section{B.1.3 VOS Lite: Transmission Capacity Value}

Given limited data on nodal prices within the power system of Jharkhand, as well as limited data on transmission needs and costs, a reliable methodology to calculate the Transmission Capacity value using only publicly available data was not pursued for the VOS Lite approach. In the results for the VOS Lite analysis (Section B.2), the Transmission Capacity Value for Jharkhand was assumed to be the same as in the VOS Full analysis for the Base Case scenario. 


\section{B.1.4 VOS Lite: Avoided Transmission and Distribution Loss Value}

The same methodology for scaling up the values for the VOS Full approach (Section A.5) was used for the VOS Lite approach. Table B- 1 shows the assumed losses and associated scale-up factor for each of the values calculated for both the VOS Full and VOS Lite approaches.

\section{B.1.5 VOS Lite: Environmental and Health Value}

The same assumptions for the marginal generator's emissions rate and the value of avoiding those emissions was assumed as in the VOS Full approach (Section A.6). Table A- 4 shows the assumptions for emissions rates and avoided emissions values used in the VOS Full and VOS Lite approaches.

\section{B.1.6 VOS Lite: RTS Integration Costs}

The same RTS Integration costs for RTS in Jharkhand was assumed to be the same for VOS Full approach (Base Case scenario) and the VOS Lite approach (Section A.7).

\section{B.1.7 VOS Lite: RTS Program Administrative Costs}

The same RTS Program Administrative costs for RTS in Jharkhand was assumed to be the same for VOS Full approach (Base Case scenario) and the VOS Lite approach (Section A.8).

\section{B.2 VOS Lite Results and Discussion}

In general, the results from both the VOS Full (Base Case scenario) and the VOS Lite approaches were similar for the Generating Capacity values and on the same order of magnitude for the Energy values. Transmission and Distribution losses, Transmission Capacity, and the Environmental and Health values were not separately calculated under the VOS Lite analysis. Table B- 2 below compares the results from the VOS Lite Analysis and the VOS Full Analysis (Base Case scenario).

Table B- 2. VOS Results for State of Jharkhand for VOS Full and VOS Lite Analyses

\begin{tabular}{|c|c|c|c|}
\hline & & \multicolumn{2}{|c|}{ Rooftop Solar (RTS) Value (INR/MWh) } \\
\hline & & VOS Full (Base Case) & VOS Lite \\
\hline & & Jharkhand & Jharkhand \\
\hline Energy & Avoided Energy Cost & $2,461.27$ & $3,213.87$ \\
\hline Generation Capacity & Avoided Capital Investment / Fixed O\&M & 14.61 & 0.05 \\
\hline Transmission Capacity & Avoided Transmission Capacity & \multicolumn{2}{|c|}{8.01} \\
\hline \multirow{4}{*}{ Environmental } & Avoided NOx Cost & \multicolumn{2}{|c|}{$1,975.69-2,392.37$} \\
\hline & Avoided SO2 Cost & \multicolumn{2}{|c|}{$2,166.09-2,809.04$} \\
\hline & Avoided CO2 Cost & \multicolumn{2}{|c|}{$1,065.10-1,640.17$} \\
\hline & Avoided PPM Cost & \multicolumn{2}{|c|}{$5.39-141.77$} \\
\hline \multirow{3}{*}{ Costs } & Solar Integration Costs & \multicolumn{2}{|c|}{-90.00} \\
\hline & Program Administration Costs & \multicolumn{2}{|c|}{-55.75} \\
\hline & & $7,550.40-9,321.49$ & $8,288.44-10,059.53$ \\
\hline
\end{tabular}


The similarity of the Generating Capacity and Energy values across the two methods provides additional confidence in the analysis' results. In both cases, the primary values for RTS in Jharkhand are the Energy and Environmental and Health values. Due to the mismatch between RTS generating hours and peak demand, RTS has little opportunity to offset the need for new generating capacity in Jharkhand. The similar Generating Capacity values are unsurprising given that most of the assumptions (e.g., the costs of the new generating unit and when the new unit would be needed) were the same. The only difference between the two approaches was in calculating the capacity credit of the RTS system, where VOS Full used net demand and VOS Lite used total demand (see Sections A.3 and B.1.2). Although of similar magnitudes, the Energy value for the VOS Lite approach is significantly higher than for the VOS Full approach. This could indicate that there is a barrier to accessing the flexibility an exchange market provides market participants, and that in practice system operators cannot always use the market to meet demand more cheaply than dispatching expensive generators, nor can they effectively sell their excess energy.

The results from VOS Lite method describe a value that is fundamentally different than those from the VOS Full approach in the following ways. First, the VOS Lite Energy value describes the marginal VOS generation as of 2019, because 2019 prices from the Indian Energy Exchange were used, whereas the VOS Full analysis is forward-looking to 2022, considering changes to the electricity generation mix to account for increased levels of demand and intermittent renewable generation. While the VOS Lite method is appropriate for low levels of incremental solar deployment or short-term applications, the VOS Full approach is more appropriate for more future-looking evaluations of VOS. This is because the power system contexts in India are changing rapidly due to, among other things, growing demand and ambitious renewable energy targets. For instance, energy values may change rapidly over the next several years as more expensive electricity generation is offset by solar, and, therefore, marginal electricity prices are depressed when solar generates; this merit order effect is not captured with the VOS Lite method because it uses a fixed set of historical prices.

Finally, the VOS Full approach uses an integrated UCED model for India, considering the impacts of solar not only at the local level, but also its effects on imports and exports from the state. The VOS Lite method, however, uses a static set of nodal prices and does not consider any indirect impacts on how solar generation in one state may impact the generation in other states, with potential impacts on electricity generation costs and the energy VOS. Given that the VOS Lite method uses historical values and is only appropriate for small incremental levels of solar, it may be more appropriate for program evaluations of current RTS policies. To understand the costs and benefits of existing RTS, one can use these simplified methods for ex post analysis to estimate the energy value that existing (or historical) solar. The shortcomings of the VOS Lite approach should be balanced against its benefits, including a simple and readily modified methodology. As it only relies on publicly available data and an Excel model, the approach can be more readily duplicated in other interested jurisdictions. Furthermore, the methodology of the analysis is transparent and more easily interpreted by power system stakeholders, potentially increasing buy-in of the results. 


\section{www.nrel.gov/usaid-partnership}

Jeremy Foster

U.S. Agency for International Development Email: jfoster@usaid.gov

\section{Sarah Lawson}

U.S. Agency for International Development Email: slawson@usaid.gov

\section{Alexandra Aznar}

National Renewable Energy Laboratory

Email: alexandra.aznar@nrel.gov

This work was authored, in part, by the National Renewable Energy Laboratory (NREL), operated by Alliance for Sustainable Energy, LLC, for the U.S. Department of Energy (DOE) under Contract No. DE-AC36-08GO28308. Funding provided by the United States Agency for International Development (USAID) under Contract No. IAG-17-2050. The views expressed in this report do not necessarily represent the views of the DOE or the U.S. Government, or any agency thereof, including USAID.

NREL/TP-6A20-78442 | January 2021

NREL prints on paper that contains recycled content.
The USAID-NREL Partnership addresses critical challenges to scaling up advanced energy systems through global tools and technical assistance, including the Renewable Energy Data Explorer, Greening the Grid, the International Jobs and Economic Development Impacts tool, and the Resilient Energy Platform. More information can be found at: www.nrel.gov/usaid-partnership.

\section{USAID RNREL}
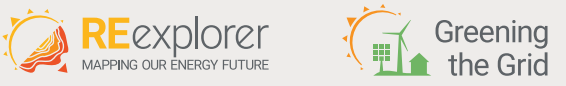

Resilient Energy 